UNIVERSIDADE DE BRASÍLIA

CENTRO DE FORMAÇÃO DE RECURSOS HUMANOS EM TRANSPORTES

MODELO DE AVALIAÇÃO DE AUTO-SUSTENTABILIDADE DA INFRAERO COMO FERRAMENTA DE AUXÍLIO À TOMADA DE DECISÕES DE INVESTIMENTOS

CLEUDES FLAUZINO GARCIA

EDUARDO PORTELA PASCOA

ORIENTADOR: JOAQUIM JOSÉ GUILHERME DE ARAGÃO, PhD

MONOGRAFIA DE ESPECIALIZAÇÃO EM GESTÃO DA AVIAÇÃo CIVIL

PUBLICAÇÃO: E-TA-006A/2007

BRASÍLIA/DF: MARÇO/2007 
UNIVERSIDADE DE BRASÍLIA

CENTRO DE FORMAÇÃO DE RECURSOS HUMANOS EM TRANSPORTES

MODELO DE AVALIAÇÃO DE AUTO-SUSTENTABILIDADE DA INFRAERO COMO FERRAMENTA DE AUXÍLIO À TOMADA DE DECISÕES DE INVESTIMENTOS

CLEUDES FLAUZINO GARCIA

EDUARDO PORTELA PASCOA

MONOGRAFIA DO CURSO DE ESPECIALIZAÇÃO SUBMETIDA AO CENTRO DE FORMAÇÃO DE RECURSOS HUMANOS EM TRANSPORTES DA UNIVERSIDADE DE BRASÍLIA, COMO PARTE DOS REQUISITOS NECESSÁRIOS PARA A OBTENÇÃO DO GRAU DE ESPECIALISTA EM GESTÃO DA AVIAÇÃO CIVIL.

APROVADA POR:

JOAQUIM JOSÉ GUILHERME DE ARAGÃO, PhD (UnB)

(Orientador)

ADYR DA SILVA, PhD (UnB)

(Examinador)

JOSÉ ALEX SANT'ANNA, PhD (UnB)

(Examinador)

BRASÍLIA/DF, 29 DE MAÇO DE 2007 


\section{FICHA CATALOGRÁFICA}

GARCIA, CLEUDES FLAUZINO e

PASCOA, EDUARDO PORTELA.

Modelo de Avaliação de Auto-Sustentabilidade da INFRAERO como ferramenta de auxílio à tomada de decisões de Investimentos.

xiii, 51p., 210x297 mm (CEFTRU/Unb, Especialista, Gestão da Aviação Civil, 2007).

Monografia de Especialização - Universidade de Brasília, Centro de Formação de Recursos Humanos em Transportes, 2007
1. Investimentos
2. Auto Sustentabilidade
3. Infra-Estrutura
4. Aeroportos/INFRAERO
I. CEFTRU/UnB
II. Título (série)

\section{REFERÊNCIA BIBLIOGRÁFICA}

GARCIA, C. F. e PASCOA, E. P. (2007). Modelo de Avaliação de Auto-Sustentabilidade da INFRAERO como ferramenta de auxílio à tomada de decisões de Investimentos, Monografia de Especialização, Publicação E-TA-006A/2007, Centro de Formação de Recursos Humanos em Transportes, Universidade de Brasília, Brasília, DF, 51p.

\section{CESSÃO DE DIREITOS}

NOME DOS AUTORES: Cleudes Flauzino Garcia e Eduardo Portela Pascoa.

TÍTULO DA MONOGRAFIA: Modelo de Avaliação de Auto-Sustentabilidade da INFRAERO como Ferramenta de Auxílio à Tomada de Decisões de Investimentos.

GRAU/ANO: Especialista / 2007

É concedida à Universidade de Brasília, permissão para reproduzir cópias desta monografia de especialização e para emprestar ou vender tais cópias somente para propósitos acadêmicos e científicos. Os autores reservam outros direitos de publicação e nenhuma parte desta monografia de especialização pode ser reproduzida sem a autorização por escrito dos autores. 


\section{DEDICATÓRIA}

Dedicamos este trabalho às pessoas mais importantes de nossas vidas: Esposas e Filhos. 


\section{AGRADECIMENTOS}

Agradecemos a Deus, pela dádiva da vida e por nos dotar de meios espirituais para a conclusão deste trabalho.

Às esposas e filhos, que sempre nos apoiaram e incentivaram e principalmente pelo amor, carinho e dedicação, fatores importantes no equilíbrio espiritual da vida de qualquer ser humano.

Aos nossos Colegas e Professores, pela espontaneidade, alegria, amizade, dedicação e entusiasmo demonstrado ao longo do curso.

À INFRAERO que nos proporcionou a oportunidade de participar de um curso tão relevante ao desenvolvimento da aviação civil.

Ao nosso orientador, Professor Joaquim José Guilherme Aragão, PhD. 


\section{RESUMO}

A obtenção e a manutenção de infra-estrutura aeroportuária e aeronáutica são atividades extremamente dispendiosas. Os grandes montantes financeiros desembolsados para este fim tornam questionável a auto-sustentabilidade econômico-financeira da INFRAERO diante de sua política de investimentos. Sabendo da importância que tem sua auto-sustentabilidade, a INFRAERO tem dentre suas metas a diminuição da quantidade de aeroportos deficitários. Contudo, a mitigação de resultados negativos deve ser acompanhada da realização de investimentos que não comprometam a auto-sustentabilidade dessa empresa. $\mathrm{O}$ modelo proposto neste trabalho tem o objetivo de ser uma ferramenta para auxiliar essa empresa na tentativa de manter sua auto-sustentabilidade no futuro diante da realização de investimentos no presente por meio de técnicas contábeis e financeiras aplicadas na avaliação de ativos e de investimentos sem perder o foco de sua missão de atender às necessidades da sociedade relativas à infra-estrutura aeroportuária e aeronáutica. 


\begin{abstract}
The obtainment and the maintenance of airports and aeronautics' infrastructure are activities extremely expensive. There are some hugs financier's amounts disburse to this way. These one become questionable the self uphold economic and financial policy of investments from INFRAERO. Knowing the importance of itself uphold, INFRAERO has got in the midst of its marks decrease of the deficit aspect from quantity of airports. At the same time, the mitigation of their results must be accompanied from of investments realization that doesn't engage the self upholds of that company. The template proposed of this monograph is the purpose of being a tool to help this organization to attempt to maintain itself uphold, in the future ahead of investments into the present by accountable and financial techniques applied on assessment of assets and investments without lose the hub of mission of attending necessities with flying field and aeronautic infrastructure.
\end{abstract}




\section{SUMÁRIO}

Tabela

Página

1 INTRODUÇÃO

1

1.1 DEFINIÇÃO DO TEMA 1

1.2 APRESENTAÇÃO 1

1.3 JUSTIFICATIVA DO TEMA 2

1.4 PROBLEMA 3

1.5 HIPÓTESE 5

$\begin{array}{lll}1.6 & \text { OBJETIVOS } & 6\end{array}$

$\begin{array}{lll}1.7 & \text { METODOLOGIA } & 7\end{array}$

2 REVISÃo BIBLIOGRÁFICA 9

2.1 AUTO-SUSTENTABILIDADE 9

2.2 INVESTIMENTO E RENTABILIDADE 11

2.2.1 Valor Presente Líquido - VPL 12

2.2.2 Taxa Interna de Retorno - TIR 13

2.2.3 Período de "Payback” 13

$\begin{array}{lll}\text { 2.2.4 Critérios a Utilizar } & 14\end{array}$

2.3 CUSTO DE CAPITAL PRÓPRIO

$\begin{array}{llllll}2.4 & \text { DEFINIÇÃO DE } & \text { INVESTIMENTO NO ÂMBITO DA }\end{array}$ $\begin{array}{ll}\text { INFRAERO } & 18\end{array}$

$\begin{array}{lll}\text { 2.4.1 Definições de Ativo e Despesas } & 19\end{array}$

2.4.2 Avaliação de Ativos 23

2.5 OUTROS BENEFÍCIOS DE UM INVESTIMENTO 26

3 DESENVOLVIMENTO DO MODELO 29

3.1 MODELO DE ADMINISTRAÇÃO DA INFRAERO 29

3.1.1 Receitas 33

3.1.2 Despesas 34

$3.2 \quad$ AUTO-SUSTENTABILIDADE DA INFRAERO 36

3.3 MENSURAÇÃO DOS FLUXOS DE CAIXA 39

3.4 A DEFINIÇÃO DO VALOR DO CUSTO DE CAPITAL 40

$3.5 \quad$ VALOR DOS INVESTIMENTOS 
3.6 MODELO DE REALIZAÇÃO DO CÁLCULO DO VALOR DE AUTO-SUSTENTABILIDADE

$4 \quad$ CONCLUSÕES

48

5

BIBLIOGRAFIA

51 


\section{LISTA DE TABELAS}

Tabela

Página

Tabela 1.1 Investimentos Totais 2007-2010

Tabela 3.1 Aeroportos INFRAERO - Maiores Lucros Entre os Anos de 2001 e 2006

Tabela 3.2 Aeroportos INFRAERO - Maiores Prejuízos Entre os Anos de 2001 e 2006

Tabela 3.3 Modelo de Avaliação de Auto-Sustentabilidade 43

Tabela 3.4 Modelo de Avaliação de Auto-Sustentabilidade 


\section{LISTA DE FIGURAS}

Figuras

Página

Figura 3.1 Representação Gráfica do Modelo de Avaliação de AutoSustentabilidade 


\section{LISTA DE GRÁFICOS}

Gráfico

Página

Gráfico 3.1 Participação das Receitas no Faturamento da INFRAERO entre os anos de 2001 e 2006

Gráfico 3.2 Participação das Despesas nos Gastos Totais entre os anos de 2001 e 2006 


\section{LISTA DE SIGLAS}

AVSEC "Aviation Security"

CAPM “Capital Asset Pricing Model” (Modelo de Precificação de Ativos)

FIPECAFI Fundação Instituto de Pesquisas Contábeis, Atuariais e Financeiras

INFRAERO Empresa Brasileira de Infra-Estrutura Aeroportuária

RCM Retorno Contábil Médio

ROI "Return On Investiment"

SUCOTAP Sistema Unificado de Cobrança de Tarifas Aeroportuárias

TECA Terminal de Cargas

TIR Taxa Interna de Retorno

TPS Terminal de Passageiros

VAE Valor Atual do Equipamento

VARLF Valor Atual das Receitas Líquidas Futuras

VAVR Valor Atual do Valor Residual

VP Valor Presente

VPL Valor Presente Líquido

WACC "Wheighted Average Cost of Capital" (Custo Médio Ponderado de Capital) 


\subsection{DEFINIÇÃO DO TEMA}

O presente trabalho de monografia tem como tema de pesquisa Investimentos em InfraEstrutura Aeroportuária. Sua delimitação está na criação de um Modelo de Avaliação de Auto-Sustentabilidade da INFRAERO como ferramenta de auxílio à tomada de decisão de investimentos.

\subsection{APRESENTAÇÃO}

A Empresa Brasileira de Infra-Estrutura Aeroportuária - INFRAERO, constituída por meio da Lei 5.862 de 12 de dezembro de 1972, vinculada ao Ministério da Defesa, é responsável pela administração dos aeroportos de todas as capitais e principais cidades brasileiras, bem assim, os pontos mais remotos de todo o território nacional. Utiliza como método de administração subsídios cruzados, em que as dependências superavitárias atendem aquelas que não se sustentam (deficitárias), em cumprimento ao seu papel de indução do desenvolvimento social-econômico regional e da integração nacional. Totaliza-se 68 aeroportos, 80 unidades de apoio à navegação aérea e 32 terminais de logística de carga.

A empresa tem como missão "Atender às necessidades da sociedade relativa à infra-estrutura aeroportuária e aeronáutica, de modo a contribuir para o desenvolvimento sustentável do Brasil, primando pela eficiência, segurança e qualidade" (BRASIL). Com efeito, deduz-se de sua missão a natureza pública de seus serviços ao verificar-se que o termo central, "infraestrutura aeroportuária e aeronáutica", está vinculado aos termos "necessidades da sociedade" e "desenvolvimento sustentável do Brasil". Ou seja, a INFRAERO se propõe a equacionar os problemas de infra-estrutura aeroportuária e aeronáutica que impedem o desenvolvimento sustentável do Brasil.

Dentro desse contexto, o presente trabalho terá como finalidade pesquisar o tema investimentos em infra-estrutura aeroportuária. Mais especificamente, será pesquisada a autosustentabilidade da INFRAERO diante da realização desses investimentos, com vistas ao desenvolvimento de um modelo de avaliação da auto-sustentabilidade da INFRAERO como ferramenta de auxílio à tomada de decisão de investimentos. 


\subsection{JUSTIFICATIVA DO TEMA}

O desenvolvimento de um país depende de uma série de fatores que vão desde a definição da política de desenvolvimento até a execução dos planos específicos nas dimensões sociais e econômicas. Portanto, o desenvolvimento sustentável baseia-se no desenvolvimento de infraestrutura que seja capaz de suportar o crescimento dos diversos setores da economia, permitindo a utilização dos elementos disponíveis que proporcionam crescimento, como é o caso do transporte aéreo.

Partindo do pressuposto que o "avião é instrumento necessário e imprescindível ao desenvolvimento" (DA SILVA, 1990, p. 93) pode-se depreender a importância do transporte aéreo frente ao desenvolvimento. Esse meio de transporte possui alta capacidade de integração entre várias regiões, dentro e fora de um país, em virtude da rapidez e segurança que proporciona aos seus usuários. Além dessas vantagens, existe também a melhora da relação custo/benefício em razão, obviamente, das facilidades das operações de transportes para o investidor, em regiões onde não existe infra-estrutura suficiente de transporte de superfície, como é o caso dos países em desenvolvimento.

O desenvolvimento de uma nação também está ligado à sua capacidade de integração entre regiões. As relações econômicas e o intercâmbio de pessoas e mercadorias têm como conseqüência natural o desenvolvimento. Nesse contexto, o transporte aéreo possui o importante papel de ser o facilitador de todas essas relações ao proporcionar integração rápida e segura entre diversas regiões de uma nação.

Com efeito, a infra-estrutura aeroportuária e aeronáutica é instrumento necessário e imprescindível ao desenvolvimento da aviação, visto que a operacionalização do transporte aéreo possui dependência direta dessa infra-estrutura. Assim sendo, a INFRAERO possui relevante missão para o desenvolvimento do Brasil, considerando que sua missão, "infraestrutura aeroportuária e aeronáutica", está vinculada "às necessidades da sociedade", denotando sua natureza de serviço público.

A infra-estrutura aeroportuária e aeronáutica é imprescindível para o crescimento da aviação que, por sua vez, é essencial ao desenvolvimento sustentável do Brasil. Diante da relevância 
da infra-estrutura aeroportuária e aeronáutica e da auto-sustentabilidade da INFRAERO para o desenvolvimento, o presente trabalho empreenderá pesquisa ao tema apresentado.

\subsection{PROBLEMA}

Observa-se que pelos investimentos já realizados é possível verificar a necessidade de vultosos desembolsos para a construção e manutenção da infra-estrutura aeroportuária.

A construção de novo terminal de passageiros com capacidade de 1 milhão pax/ano, considerado pequeno, como é o TPS do Aeroporto de Porto Velho, pode custar cerca de R\$ 12 milhões. Esse valor corresponde a um dos menores investimentos realizados pela INFRAERO nos últimos anos. A ampliação da capacidade do TPS do Aeroporto Internacional de Salvador de 2,5 para 6 milhões de pax/ano custou cerca de R \$ 232 milhões. Cerca de 61 milhões foram utilizados ns obras de ampliação e reforma do terminal de passageiros, implantação do pátio de cargas e reforço do pátio de aeronaves do Aeroporto Internacional de Cuiabá, tendo sido concluída em 2006.

Existe previsão de realização de investimentos em infra-estrutura aeroportuária no montante de R 3 bilhões, em virtude do Programa de Aceleração do Crescimento (PAC) empreendido pelo Governo Federal. Esses valores serão investidos entre os anos de 2007 e 2010, contemplando 20 (vinte) aeroportos. Desse montante, R\$ 968,6 milhões sairão dos cofres da INFRAERO, conforme previsto no PAC. A Empresa conta, ainda, em seu planejamento com um acréscimo de investimentos referente ao ATAERO (Adicional de Tarifas Aeroportuárias). 
Tabela 1.1 - Investimentos Totais 2007-2010

\begin{tabular}{l|r|r|r}
\multicolumn{1}{c|}{ REGIÃo } & Governo Federal & \multicolumn{1}{c}{ INFRAERO } & \multicolumn{1}{c}{ TOTAL milhões) } \\
\hline Região Norte & 69,7 & 25,4 & 95,1 \\
Região Nordeste & 134,6 & 16,2 & 150,8 \\
Região Sudeste & $1.263,3$ & 537,7 & $1.801,0$ \\
Região Sul & 305,5 & 295,5 & 601,0 \\
Região Centro-Oeste & 259,0 & 93,7 & 352,7 \\
\hline \multicolumn{1}{c}{ Total } & $\mathbf{2 . 0 3 2 , 0}$ & $\mathbf{9 6 8 , 6}$ & $\mathbf{3 . 0 0 0 , 6}$ \\
\hline
\end{tabular}

Fonte: INFRAERO

Diante disso, percebe-se que desembolsos para criação e manutenção de infra-estrutura aeroportuária apresentam grandes quantias. Torna-se pertinente à preocupação com a rentabilidade desses investimentos, considerando que, se deficitários, podem gradativamente, comprometer a auto-sustentabilidade da INFRAERO, comprometendo um dos elementos alavancadores de desenvolvimento que é a aviação civil. Ou seja, existe o risco de diminuição da capacidade de investimento da INFRAERO.

Apesar de que, historicamente, as demonstrações financeiras da INFRAERO trazem resultados positivos, o grande montante de investimentos realizados em infra-estrutura aeroportuária coloca em risco o equilíbrio financeiro da Empresa. Pois o histórico de resultados positivos não é garantia de que os investimentos realizados poderão apresentar bons resultados no futuro. É possível que esses investimentos venham prejudicar a saúde financeira da Empresa.

Outro fator de risco é que a política de investimentos nem sempre está orientada pelos fatores econômico-financeiros do negócio. Não que estes fatores sejam os mais importantes, porém muitas vezes, os investimentos são realizados com objetivos sociais e de desenvolvimento regional. Ações de investimentos que não se preocupam com os aspectos de rentabilidade podem comprometer a auto-sustentabilidade da INFRAERO, diminuindo sua capacidade de contribuir continuamente para o desenvolvimento sustentável do país. 
Ademais, os valores desembolsados pela INFRAERO na criação e manutenção de infraestrutura aeroportuária e aeronáutica não são contabilizados em seu ativo. Isto porque os aeroportos recebedores dos investimentos fazem parte do acervo da União. A INFRAERO possui a peculiaridade de realizar investimentos em bens que não lhes pertencem. Esta é uma questão que influencia a auto-sustentabilidade dessa empresa, pois não há garantia do retorno financeiro de todos esses desembolsos realizados sejam em seu benefício.

Enfim, o problema colocado está relacionado à incerteza acerca da auto-sustentabilidade da INFRAERO em virtude de:

- realização de desembolso a título de investimentos em infra-estrutura aeroportuária e aeronáutica, sem que haja uma definição clara do que seja um indicador de autosustentabilidade dessa empresa;

- não existir termo jurídico completo (com prazos, condições e valores) que estabeleça regras acerca da exploração dos aeroportos. Ou seja, não há garantias reais de que a INFRAERO receberá o benefício financeiro decorrente da realização de seus investimentos em bens da União.

Por fim, a delimitação do problema apresentado está no seguinte questionamento: É possível construir um modelo matemático de avaliação de auto-sustentabilidade da INFRAERO utilizando-se dos conceitos de Avaliação de Investimentos?

Maior ênfase será despendida à inexistência do que seja um indicador de autosustentabilidade da INFRAERO. O objetivo do trabalho está direcionado à discussão desse problema. Porém à parte do problema relacionado à inexistência do termo jurídico mencionado não será motivo de profunda pesquisa, sendo apenas apresentadas algumas informações e argumentações necessárias à discussão da parte do problema que trata da rentabilidade que garanta a continuidade dos investimentos.

\subsection{HIPÓTESE}

Considerando-se o problema levantado, pode-se supor que, com sucessivas decisões de investimentos em projetos deficitários, a INFRAERO não seja capaz de gerar recursos que 
garantam a auto-sustentabilidade do seu negócio. Esta é uma hipótese que pode ser colocada à prova por meio de pesquisa envolvendo a projeção de resultados financeiros.

Porém, para fazer frente à parte do problema, eleita para efeito deste trabalho, a hipótese construída apresenta-se da seguinte forma:

É possível construir, com base em conceitos de avaliação de investimentos, um modelo de avaliação que permita aos gestores a verificação da auto-sustentabilidade da INFRAERO de modo a tomar decisões de investimentos que contribuam para o desenvolvimento sustentável do Brasil sem comprometer a saúde financeira da empresa.

Acredita-se que o desenvolvimento deste trabalho auxiliará as decisões de investimento com vistas ao cumprimento da missão da INFRAERO, sem comprometer sua saúde econômicofinanceira, uma vez que o modelo desenvolvido permitirá uma perspectiva de autosustentabilidade financeira dessa Empresa de modo diferente do vislumbrado até o momento.

\subsection{OBJETIVOS}

Por oportuno, o presente trabalho tem como objetivo geral o desenvolvimento de um modelo de avaliação da auto-sustentabilidade da INFRAERO que seja capaz de gerar informações relevantes à tomada de decisão de investimentos.

Serão perseguidos os objetivos específicos de modo a atingir o objetivo geral, quais sejam:

- pesquisar os conceitos de sustentabilidade e auto-sustentabilidade de modo a delimitar a forma de utilização desses conceitos;

- pesquisar os conceitos pertinentes à avaliação de investimentos no âmbito da administração financeira e da contabilidade com vistas a complementar o conceito de auto-sustentabilidade de investimentos;

- pesquisar a forma de tratamento dos investimentos pela INFRAERO e suas implicações na auto-sustentabilidade dessa empresa, considerando sua missão institucional inserida no contexto do desenvolvimento brasileiro;

- construir o modelo de avaliação proposto na delimitação do tema. 
Cabe ressaltar, que o trabalho não será um indicador de perdas ou ganhos em investimentos realizados. Ou seja, a análise de determinado projeto de investimento ou de todos os investimentos da INFRAERO não está entre os objetivos. Esta colocação se faz necessária para que o trabalho não se resuma em mera análise de projetos de investimentos.

O referido modelo de decisão de realização de investimentos deve levar em consideração as necessidades financeiras dos aeroportos e as necessidades da política de desenvolvimento econômico e social do país. Deve ser capaz de vislumbrar o impacto da realização de um investimento no resultado financeiro da INFRAERO em períodos futuros.

O modelo de decisão de investimento terá como objetivo fornecer informações que permitam aos gestores visualizar os valores reais dos investimentos, por meio das técnicas de administração financeira e de alguns conceitos que dizem respeito à mensuração de ativos.

\section{$1.7 \quad$ METODOLOGIA}

O método científico a ser aplicado no presente trabalho de pesquisa será o dedutivo. Pois, a partir da definição do conceito de auto-sustentabilidade, surgirá à necessidade de definição de uma série de outros conceitos tais como o de Avaliação e Análise de Investimentos.

Os referidos conceitos serão definidos por meio de pesquisa bibliográfica. De modo complementar, será pesquisada a realidade da INFRAERO no que tange ao tratamento contábil de seus investimentos.

Por fim, a avaliação dos aspectos que dizem respeito ao investimento no setor público, sua avaliação e a definição dos conceitos mencionados serão as premissas necessárias para o desenvolvimento de um modelo específico de avaliação da auto-sustentabilidade da INFRAERO. Essas definições serão avaliadas em sinergia à realidade do modelo de administração de aeroportos da INFRAERO. Dessa forma, será desenvolvido o modelo proposto levando em consideração os objetivos da política de desenvolvimento da infraestrutura da aviação civil no contexto do desenvolvimento brasileiro.

Cabe ressaltar que, em virtude do modelo de administração de aeroportos que se equilibram financeiramente, como ocorre no caso da INFRAERO, os investimentos não serão 
contemplados individualmente, mas dentro de um contexto geral. Em outras palavras, a partir desse modelo de administração de aeroportos, com o desenvolvimento de pesquisa bibliográfica pretende-se chegar a um modelo decisório compatível com esse modelo de administração. 


\section{REVISÃO BIBLIOGRÁFICA}

\subsection{AUTO-SUSTENTABILIDADE}

O termo sustentabilidade é usualmente utilizado com referência a sustentabilidade ambiental.

A partir da década de noventa, com a ECO-92, ampliou-se sua utilização a outros aspectos, tais como: sustentabilidade econômica, social, institucional, financeira etc. Numa visão econômico-financeira, sustentabilidade pode significar o retorno financeiro de um projeto, permitindo o seu funcionamento de forma efetiva, mesmo depois que a assistência financeira que lhe é oferecida acabar.

Araújo (2005, p. 9) define sustentabilidade mais amplamente como "a capacidade de ser um empreendimento sustentável, que se pode manter mais ou menos constante ou estável, por um longo período, sendo tal estabilidade em termos institucionais, técnicos, políticos e financeiros". Para ele "a necessidade que as organizações têm de gerar recursos próprios para financiar suas atividades" deve ser chamada de auto-sustentabilidade. Esta última definição será a escolhida para o desenvolvimento da pesquisa em questão.

Os conceitos de sustentabilidade e auto-sustentabilidade são amplamente utilizados no âmbito das organizações do terceiro setor. O motivo da utilização de tais conceitos por essas organizações em lugar de conceitos de rentabilidade máxima de investimentos é de que as organizações não são um fim em si mesmas e que seus objetivos poderiam ser preteridos a um segundo plano caso os resultados financeiros sejam a meta principal desses organismos.

A INFRAERO, inserida no contexto de infra-estrutura para o desenvolvimento da aviação civil, assim como as organizações do terceiro setor, não é um fim em si mesma, pois também possui uma missão social. Por conseguinte, seu objetivo principal não é a geração de resultados financeiros máximos, mas é possível abstrair de sua missão o objetivo de garantir resultados financeiros mínimos para que a atividade de investimentos em infra-estrutura aeroportuária não seja prejudicada. A auto-sustentabilidade, portanto, não é o objetivo principal a ser atingido, mas é um requisito para que haja desenvolvimento sustentável. 
Da Silva (1990) alerta para o fato de que a gestão dos aeroportos deve buscar meios para alcançar a auto-suficiência financeira ou mantê-la, caso já alcançada. Essa preocupação é pertinente, visto que a continuidade de qualquer negócio depende do retorno que ele proporciona ao empreendedor. Mesmo um negócio sem fins lucrativos deve ser rentável para que tenha garantido a continuidade de suas atividades.

No que tange à infra-estrutura aeroportuária, não poderia ser diferente. O negócio possui a necessidade de que sua operação seja rentável. O aeroporto é também uma empresa e deve ser tratado como tal. Sua administração deve inteirar-se de todas as condições pertinentes ao gerenciamento do negócio tais como as condições econômico-financeiras de seus investimentos, aproveitando ao máximo seus recursos de forma a buscar melhores índices de eficiência operacional. Torna-se necessária à aplicação de conceitos avançados para a tomada de decisões. Um exemplo desses conceitos é o método de gestão baseado na margem de vendas e no giro dos ativos do negócio denominado ROI ("Return On Investiment").

Com efeito, pode-se considerar auto-sustentável a empresa que seja capaz de gerar recursos suficientes para a continuidade do negócio por um longo período de tempo e para remunerar o capital nela empregado.

Ou seja, o requisito mínimo para que uma empresa seja auto-sustentável é ser capaz de gerar recursos suficientes para o pagamento do investimento realizado, remunerando o capital empregado a uma determinada taxa de juros.

Porém, apenas a viabilidade econômica dos investimentos envolvidos não seria suficiente para determinar se a INFRAERO é, de fato, auto-sustentável. Também não é possível confirmar sua auto-sustentabilidade por meio da verificação de seus resultados financeiros em determinado período.

Torna-se necessário verificar a viabilidade econômica dos investimentos em determinado horizonte de tempo (vida útil dos investimentos), bem como a liquidez da empresa ao longo desse mesmo horizonte. Em outras palavras, a INFRAERO pode apresentar previsão de bom retorno financeiro ao longo de 20 anos, mas em determinado período não possuir disponibilidade de caixa para realizar os pagamentos necessários à manutenção do negócio. 
A INFRAERO possui um histórico de realização de lucros ao longo de sua existência, sendo considerada uma empresa auto-sustentável do ponto de vista contábil. Em exame às informações contábeis dessa empresa nos últimos seis anos, é possível verificar que o lucro acumulado nesse período é decorrente de resultados positivos em 64 dependências que compensam os resultados negativos das outras 33 .

Ações têm sido empreendidas no sentido de diminuir o número de aeroportos com rentabilidade negativa. Um indicador de que a empresa tem se preocupado com os aspectos econômico-financeiros na gestão de investimentos em aeroportos é o fato de que antes da tomada de decisão de investir em determinado aeroporto, são realizados estudos de viabilidade econômica e análise financeira de projetos, em que são aplicados conceitos avançados de análise de investimentos.

Portanto, Auto-Sustentabilidade define-se, neste trabalho como a capacidade de gerar recursos suficientes para o pagamento dos investimentos realizados, remunerando o capital empregado a uma determinada taxa de juros. Porém, não apenas isso. Pois, além de gerar recursos para pagamento dos investimentos realizados é necessário gerar recursos constantemente, no intuito de não haver necessidade de aporte de recursos ao longo da duração dos projetos.

\subsection{INVESTIMENTO E RENTABILIDADE}

Visto que o requisito mínimo da auto-sustentabilidade é possuir capacidade de gerar recursos suficientes para o pagamento dos investimentos realizados, remunerando o capital empregado a uma determinada taxa de juros, necessário se faz definir os termos Investimento e Rentabilidade.

Investimentos representam todos os dispêndios necessários para colher um novo benefício ou para manter um benefício conquistado. O benefício financeiro a ser conquistado com a realização de determinado investimento pode ser denominado rentabilidade. É vasta a bibliografia acerca da avaliação de investimentos e verificação de sua rentabilidade. Estes conceitos são amplamente conhecidos no campo da Administração Financeira dentro do assunto Orçamento de Capital. 
Orçamento de Capital se refere ao processo de alocação ou aplicação de capital em ativos fixos, conforme é explicado por Ross, Westerfield e Jordan (2000). Também entram no campo do Orçamento de Capital as decisões quanto ao financiamento das operações do negócio, mas, segundo estes autores, o ativo fixo é que define o negócio da empresa.

Para entender o conceito de investimentos e rentabilidade, antes se torna necessário ter idéia do que seja o valor do dinheiro no tempo. O valor de 1 (uma) unidade monetária hoje não possui o mesmo poder de compra de 1 (uma) unidade monetária amanhã. Para tratar desses valores há que se aplicar o conceito de valor presente.

"Valor presente é o valor atual de um pagamento ou de recebimento futuro, considerando determinada taxa de desconto. Podemos também ter o valor presente de uma série de recebimentos futuros" (SILVA, 2001, p. 163).

Em decorrência desse conceito, dentre as várias alternativas de investimento que as empresas têm à sua disposição, algumas possuem valor e outras não. Algumas ajudam no crescimento do negócio, enquanto outras são o caminho para o fim do mesmo.

Enfim, a Administração Financeira deve identificar quais os investimentos apresentam potencial ganho de valor e quais destroem valor. Adiante, serão demonstradas as principais técnicas de avaliação de projetos de investimentos decorrentes do estudo de Orçamento de Capital.

\subsubsection{Valor Presente Líquido - VPL}

O VPL de um investimento corresponde à diferença entre o seu valor de mercado e seu custo.

Ele é estimado calculando-se o valor presente dos fluxos de caixa futuros, para estimar o valor de mercado, e a seguir subtrai-se o custo. Em outras palavras, o VPL é uma medida de quanto valor é criado ou adicionado hoje por realizar um investimento. Este critério de avaliação é o mais aconselhável pelos estudiosos da Administração Financeira, sendo representado graficamente da seguinte forma:

$$
\mathrm{VPL}=\left[\mathrm{FC}_{1} /(1+\mathrm{i})^{1}+\mathrm{FC}_{2} /(1+\mathrm{i})^{2}+.+\mathrm{FCt} /(1+\mathrm{i})^{\mathrm{t}}\right]-\text { Investimento Inicial }
$$


Ou ainda:

$\mathrm{VPL}=\sum_{t=1}^{n} \frac{F C_{t}}{(1+i)^{t}}-$ Investimento Inicial

Onde:

FC - Fluxo de Caixa Gerado;

i - Taxa de Desconto;

$\mathrm{t}$ - Número de períodos.

\subsubsection{Taxa Interna de Retorno - TIR}

Trata-se da "taxa de desconto que faz com que o VPL de um investimento seja nulo" (ROSS; WESTERFIELD; JORDAN, 2000, p. 223). Percebe-se que esta taxa está intimamente relacionada com o VPL. A TIR é uma tentativa de obter uma única taxa de retorno para sintetizar os méritos de um projeto. É interna porque depende unicamente dos fluxos de caixa de determinado investimento.

Esta taxa também é conhecida como retorno do fluxo de caixa descontado. Determinado investimento deve ser aceito quando a TIR é maior que o retorno exigido. Porém deve-se considerar o fato de que este método de avaliação não deve ser utilizado para comparação de projetos mutuamente excludentes, pois nesses casos o projeto com a maior TIR nem sempre é o que cria mais valor para a empresa.

O método para calcular a TIR de determinado projeto é de tentativa e erro utilizando a fórmula de cálculo do VPL. Esse cálculo pode ser facilitado pelo uso de planilhas eletrônicas como o Microsoft Excel.

\subsubsection{Período de "Payback"}

$\mathrm{Na}$ análise de um projeto de investimento é muito comum que surja a questão de prazo de recuperação do valor investido. A técnica capaz de fornecer resposta a esse tipo de questionamento é a regra do período de "Payback". "O período de payback é o tempo necessário para recuperar um investimento" (ROSS; WESTERFIELD; JORDAN, 2000, p. 218). 
Esta técnica informa a quantidade de anos de espera para que os fluxos de caixa acumulados de um investimento se igualem ou superem o seu custo. Baseando-se nesta técnica, um projeto de investimento deve ser aceito quando o período de "payback" for menor ou igual a um número pré-determinado de anos.

Para o seu cálculo considera-se que as entradas de caixa ocorrem de maneira uniforme durante o ano. Dada uma projeção de entrada de caixa no valor de $\mathrm{R} \$ 100,00$ no primeiro ano, o método do período de "Payback" considera que ocorrerão entradas diárias de R 0,28 (R\$100 / 360 dias). O período de "Payback" pode ser obtido pela relação entre o valor do investimento necessário e o valor do fluxo anual líquido das entradas de caixa.

Vários autores consideram que a regra do período de "Payback" é um critério deficiente por ignorar o risco envolvido no projeto, o valor do dinheiro no tempo e os fluxos de caixa além do período de corte.

\subsubsection{Critérios a Utilizar}

Existem ainda outros critérios para avaliação de investimentos como o Retorno Contábil Médio (RCM) e Índice de Rentabilidade. Porém, os critérios apresentados são os mais difundidos na administração financeira. Dentre eles, os que apresentam as conclusões mais aceitáveis são o VPL e a TIR por apresentarem resultados mais úteis à tomada de decisão de investimentos.

A técnica de VPL é mais recomendada na bibliografia, por ser a que apresenta informação relevante para os investidores. Tal informação é relativa ao caixa gerado por determinado negócio e se trata da comparação entre os valores a serem realizados e valor investido. O que importa para os investidores é o valor gerado por meio de variação do caixa. Além disso, outros critérios não consideram o valor do dinheiro no tempo. A isso se deve a preferência pelo VPL.

A utilização dessa técnica do VPL para avaliação de investimentos será preferida a outras técnicas, em virtude da argumentação já apresentada. 


\subsection{CUSTO DE CAPITAL PRÓPRIO}

A utilização de uma taxa de juros para realização do desconto dos fluxos de caixa futuros é imprescindível na técnica do VPL. A questão que se faz presente é: que taxa utilizar?

Poderia ser considerada, para efeito de avaliação de investimentos, a taxa livre de risco no mercado financeiro. Mas, utilizar essa taxa equivaleria a aceitar expor o capital próprio ao risco para receber a mesma remuneração de quem não expõe seu capital. Em outras palavras, somente é aceitável investir quando a taxa de retorno do investimento for equivalente à taxa de retorno oferecida pelo mercado financeiro num investimento de risco equivalente. Isto se trata de uma regra de decisão de investimento:

"A taxa de desconto de um projeto deve ser o retorno esperado de um ativo financeiro de risco comparável.” (ROSS; WESTERFIELD; JAFFE, 2002, p. 257)

Portanto, a utilização da taxa livre de risco descarta-se dessa discussão. A taxa referida por Ross como o retorno esperado trata-se do Custo de Capital Próprio. Este conceito se assemelha ao conceito de Custo de Oportunidade.

O Custo de Oportunidade não se trata de um desembolso realizado. Ele requer que haja desistência da obtenção de um benefício. Trata-se do valor que o investidor deixa de obter para a realização de um investimento. Nas palavras de Ross, Westerfield e Jordan (2000, p. 241), o Custo de Oportunidade é a alternativa de maior valor sacrificada em favor de um determinado investimento.

O Custo de Oportunidade está associado ao investimento a ser realizado. A questão é identificar que alternativas estão sendo desprezadas na escolha de um investimento. Após a identificação, o próximo passo é mensurar cada uma dessas alternativas e eleger a de maior valor como o Custo de Oportunidade da realização do investimento.

Investir em um projeto que cubra o custo de oportunidade não é garantia de que o investimento seja rentável, ou ainda, não é garantia de que sejam atendidas as expectativas dos investidores. Um dado investimento com $10 \%$ de retorno pode cobrir uma taxa de custo de oportunidade de $3 \%$ sem atender ao que era esperado pelos investidores se sua expectativa 
de retorno fosse $9 \%$ de retorno já descontado a taxa do custo de oportunidade. Neste caso a taxa de retorno do investimento deveria atingir $12 \%$ para que as expectativas fossem atendidas.

Isso ocorre porque a expectativa de ganho dos investidores não é determinada simplesmente pelas alternativas disponíveis. Os investidores esperam que determinado empreendimento seja remunerado a uma taxa que seja compatível com o risco envolvido de sua operação. Em outras palavras, para realização de um investimento torna-se necessário que o capital a ser investido tenha uma remuneração mínima como prêmio pelo risco do investimento.

Os recursos aplicados em uma empresa, seja qual for à origem deles, devem ser remunerados.

Os recursos próprios são remunerados por meio dos lucros e os recursos de terceiros remuneram-se pelos juros da fonte de financiamento. Estas informações podem ser confirmadas na obra de Casarotto Filho (1996).

A taxa de remuneração desses recursos é conhecida na bibliografia como Custo de Capital. Kuster e Nogacz definem como Custo de Capital o custo dos recursos financeiros próprios e/ou de terceiros utilizados pela empresa em seu ciclo operacional ou empreendimento. De uma maneira simples pode-se definir o Custo de Capital como custo geral da organização para obtenção de recursos para investimento, inclusive por dívidas ou recursos próprios.

O cálculo do custo de capital pode permitir que o valor de uma empresa seja avaliado, uma vez que a partir da taxa do custo de capital pode-se utilizar o método do fluxo de caixa descontado, um dos métodos mais utilizados para o fim de avaliação do valor de ativos de um modo geral.

Nesse mesmo sentido Martins (1997, p. 122) se pronuncia:

"É comum hoje dizer que o valor econômico de qualquer bem corresponde ao valor presente do fluxo líquido de caixa que se espera que esse bem produza no futuro. O mesmo aplica-se ao caso da empresa como um todo."

O custo de capital de uma empresa depende da composição dos capitais que a estruturam. 
Esse custo pode ser mensurado pela média ponderada do custo de capital próprio e de capital de terceiros. Essa metodologia de cálculo é apresentada por Ross, Westerfield e Jordan (2000) como o Custo Médio Ponderado de Capital ou WACC (Wheighted Average Cost of Capital).

O custo de capital representa uma taxa mínima que a empresa precisa obter em suas operações, o que indica assim a remuneração mínima necessária para manter o valor do empreendimento.

Considerando-se a realidade da INFRAERO, apenas será levado adiante neste trabalho, o Custo de Capital Próprio. Isto porque essa empresa não realiza captação de recursos junto ao mercado financeiro.

Custo de Capital pode, então, ser definido como a taxa de remuneração justa pela exposição ao risco em determinado investimento. Ou seja, ele será a taxa mínima esperada de retorno.

Por meio dessa taxa pode-se avaliar o valor presente dos fluxos de caixa futuros e verificar se os retornos de caixa pagam os desembolsos realizados a título de investimentos.

Enfim, daí pode-se depreender que Custo de Capital é aquela taxa que garante a autosustentabilidade do capital investido, pois proporciona o retorno esperado pelos investidores continuamente, pois, além de garantir retorno, não permite a corrosão dos recursos financeiros ao longo do tempo.

É pertinente ressaltar que o Custo de Capital da realização de um novo projeto pode não ser o mesmo da empresa que realiza o investimento. Caso novos projetos sejam avaliados com base em um Custo de Capital determinado pelo risco geral da empresa, corre-se o perigo de aceitar projetos de risco elevado e rejeitar todos os projetos de baixo risco.

Isto ocorre porque os fluxos de caixa do investimento de alto risco terão um VPL bem maior que os fluxos dos investimentos de baixo risco, em virtude da não utilização da taxa de custo de capital justa pelo risco envolvido nos investimentos. 
No entanto, a taxa do Custo de Capital da INFRAERO é a taxa mais adequada para efetuar descontos de fluxos de caixa futuros de seu negócio, pois traduzem o retorno mínimo esperado pelos acionistas de modo geral.

\subsection{DEFINIÇÃO DE INVESTIMENTO NO ÂMBITO DA INFRAERO}

Antes de dar continuidade ao raciocínio que se dirige ao modelo de avaliação de autosustentabilidade é preciso tecer algumas considerações acerca da definição de investimentos no âmbito da INFRAERO.

No que se refere aos investimentos realizados com recursos próprios da INFRAERO, por serem os mesmos realizados em bens da União, representados por obras e serviços de engenharia e modernização da infra-estrutura aeroportuária, a Empresa efetua tais registros para fins societários e fiscais como despesa, haja vista que os aeroportos são bens públicos pertencentes à União (Art. 38 do Código Brasileiro de Aeronáutica, Lei 7.565, de 19 de dezembro de 1986).

Desse modo, a INFRAERO não registra tais investimentos no seu Ativo Permanente, embora seja claro que os mesmos mantêm a capacidade de geração de resultados futuros. Além disso, inexiste termo de concessão entra a União e a INFRAERO, que estabeleça condições relativas à atribuição de valor econômico aos investimentos realizados e mecanismos de indenização em caso da substituição/retirada de aeroportos da rede.

O Plano de Contas da INFRAERO traz dentre suas despesas a conta "Expansão e Modernização de Aeroportos" com a seguinte descrição:

"São as despesas executadas com recursos próprios da empresa, com investimentos em bens, em construção, em edificações aeroportuárias e em órgãos do sistema de proteção ao vôo, que não podem fazer parte do ativo próprio da empresa por pertencerem ao acervo da união”.

Esta conta não é considerada um investimento no Balanço Patrimonial da empresa por se tratar de uma aplicação em bens que não fazem parte de seu ativo. A INFRAERO parte do pressuposto de que somente podem ser classificados como investimentos, os gastos aplicados em ativos da empresa. 
Apesar de tratar-se de um dispêndio necessário para colher um novo benefício ou para manter um benefício conquistado, contabilmente, a conta é considerada uma despesa, impactando no resultado do exercício social.

\subsubsection{Definições de Ativo e Despesas}

Partir dos conceitos definidos pela Teoria Contábil será a ação a ser tomada para se chegar às conclusões sobre a classificação dos investimentos realizados pela INFRAERO em seu Balanço Patrimonial e sua Demonstração do Resultado do Exercício.

Segundo Francisco D’Auria, (apud IUDÍCIBUS, 2000, p. 129), o ativo é "o conjunto de meios ou a matéria posta à disposição do administrador para que este possa operar de modo a conseguir os fins que a entidade entregue à sua direção tem em vista”. Para Iudícibus (2000) esta definição é, de certa forma, restrita, pois fala em conjunto de meios materiais ou tangíveis, deixando de lado elementos tão importantes como goodwill, cujo conceito também será explorado no decorrer do trabalho.

Hendriksen e Breda (1999) afirmam que "ativos devem ser definidos como potenciais fluxos de serviço ou como direitos a benefícios futuros sob o controle da organização." Neste mesmo sentido, Iudícibus (2000) argumenta que o ativo deve ser considerado à luz da sua propriedade e/ou à luz de sua posse e controle, que precisa estar incluído no ativo, em seu bojo, algum direito específico a benefícios futuros ou, em sentido mais amplo, o elemento precisa apresentar uma potencialidade de serviços futuros (fluxos de caixas futuros) para a entidade.

Partindo dessas definições, pode-se depreender que os investimentos realizados pela INFRAERO nos aeroportos por ela administrados poderiam ser classificados como ativos em seu balanço patrimonial, visto que essa empresa detém o controle ou a posse desses aeroportos que recebem seus investimentos.

Apesar de não existir documento que forneça garantias de prazo para a exploração dos aeroportos, pode-se considerar que tais investimentos constituem direitos específicos a benefícios futuros, visto que representam fluxos de caixas futuros a serem recebidos pela INFRAERO. 
A definição do que seja Despesa também não favorece a posição assumida pela empresa.

"Despesa, em sentido restrito, representa a utilização ou o consumo de bens e serviços no processo de produzir receitas" (IUDÍCIBUS, 2000, p.155).

No caso de um aeroporto, a produção de receitas ocorre durante a sua operação. A realização de investimentos para a construção e/ou ampliação de infra-estrutura aeroportuária não se trata de consumo para produção de receitas.

Pode-se, de modo grosseiro, comparar um gasto com a construção de um aeroporto pela INFRAERO com um gasto na aquisição de uma máquina industrial por um fabricante de refrigerantes. A compra da máquina não é garantia de que a receita com a venda de refrigerantes seja realizada. $\mathrm{O}$ esforço empregado na operação dessa máquina é que poderá ser considerado despesa. Ou seja, os gastos da operação aeroportuária serão considerados como despesa, e não a construção, ampliação ou aquisição de um aeroporto.

O motivo pelo qual os investimentos não são contabilizados no Balanço Patrimonial da INFRAERO é a inexistência de termo jurídico que conceda à INFRAERO a administração e exploração da infra-estrutura aeroportuária. Não há termo jurídico que indique as condições dessa concessão tais como objeto, prazo e condições essenciais. A inexistência desse termo faz com que os gastos realizados para construção e/ou ampliação de infra-estrutura aeroportuária sejam contabilizados como despesas.

No entanto, o valor econômico da INFRAERO está intimamente ligado à realização de investimentos na infra-estrutura aeroportuária. Na literatura contábil, o valor de uma empresa é avaliado pelo valor de seus ativos, ou seja, o valor presente dos potenciais fluxos de caixas futuros gerados pela operação do negócio. As receitas da INFRAERO são originárias da operação e exploração comercial de aeroportos quais sejam: Receitas Aeronáuticas (Tarifa de Embarque, Pouso e Permanência de Aeronaves nos aeroportos), Receitas Comerciais (Terminais de Carga, Concessão de Áreas para Atividades Comerciais). Ou seja, os fluxos de caixa futuros esperados pela INFRAERO têm sua origem na posse da administração e exploração de aeroportos pertencentes à União. 
Portanto, no valor de seus ativos deveria constar o valor do direito de administrar e explorar a infra-estrutura aeroportuária dos aeroportos incorporados a ela para uma avaliação mais perfeita do patrimônio da INFRAERO.

Embora, essa contabilização possa ser justificada com base na definição encontrada na literatura para Ativo e Despesa, a INFRAERO continua a realizar a contabilização desses investimentos como despesa, pois dessa forma é contemplada com um benefício fiscal: a redução do pagamento de Imposto de Renda cobrado sobre o lucro, visto que a despesa tem impacto negativo sobre o resultado do exercício, diminuindo a base de cálculo desse tributo.

Outro ponto é que, uma vez realizado determinado gasto na construção de infra-estrutura aeroportuária, a INFRAERO não possui o direito de vendê-la ou concedê-la a outrem, como no caso da aquisição de uma máquina por um fabricante de refrigerantes.

Ocorre que, para realização de gestão dos investimentos realizados, a empresa necessita de informações acerca da geração de valor desses investimentos. Dessa forma, a despesa "Expansão e Modernização de Aeroportos" pode ser considerada um investimento do ponto de vista gerencial.

Em outras empresas também existem gastos que, contabilmente devem ser tratados como despesa e que, gerencialmente, devem ser tratados como investimentos por beneficiarem exercícios financeiros futuros como, por exemplo, gastos em campanhas publicitárias lançadas em seu período de competência e que contribuem para o aumento das vendas em períodos futuros.

A FIPECAFI (2000, p. 206), no Manual de Contabilidade das Sociedades por Ações, demonstra como deve ser o tratamento contábil de investimentos realizados para expansão de empresas, para pesquisas e desenvolvimento de produtos, implantação de sistemas e métodos.

Esses e outros gastos podem ser, em determinadas condições, contabilizados no grupo de Ativo Diferido. São contabilizados neste grupo "as aplicações de recursos em despesas que contribuirão para a formação do resultado de mais de um exercício social". 
Os investimentos em infra-estrutura aeroportuária realizados pela INFRAERO poderiam encaixar-se neste grupo, haja vista sua característica de formação de resultados futuros. No entanto, a lei 6.404/76 estabelece que a avaliação do Ativo Diferido seja feita pelo valor do capital aplicado.

A INFRAERO não pode realizar esse tipo de registro, uma vez que o valor investido em infra-estrutura aeroportuária não pode ser considerado ativo de sua propriedade. A lei estabelece ainda que a amortização desses ativos deva ser feita "em prazo não superior a dez anos, a partir do início da operação normal ou do exercício em que passem a ser usufruídos os benefícios deles decorrentes".

A INFRAERO vem tomando providências no sentido de resolver este entrave contábil que trás implicações à sua auto-sustentabilidade. Um grupo de trabalho vem realizando estudos para o reconhecimento desses ativos intangíveis no Balanço Patrimonial da empresa.

Esse problema se trata de algo relevante, visto que pode ter implicações negativas quando da tentativa de captação de recursos no mercado. Trata-se inclusive de um entrave à abertura de capital da empresa. Pois nenhum investidor alocaria recursos em uma empresa que realiza investimentos em bens de outra entidade sem garantias de realização dos benefícios decorrentes do investimento.

A interrupção de fluxos de caixa que lhe seriam de direito é um risco atrelado ao negócio da INFRAERO.

Diante disso, por enquanto resta à INFRAERO, apenas para efeitos gerenciais de tomada de decisões de investimentos, considerar a avaliação dos fluxos de caixa futuros dos empreendimentos realizados.

Os investimentos realizados pela INFRAERO com recursos próprios serão considerados para efeito deste trabalho, como ativos para que com base nessa definição, possam ser corretamente avaliados. 


\subsubsection{Avaliação de Ativos}

O conceito de ativo discutido na Teoria Contábil induz ao pensamento de que os benefícios futuros a serem conseguidos pela INFRAERO, em virtude de investimentos realizados em infra-estrutura aeroportuária, fazem parte de seu patrimônio. Os aeroportos fazem parte do acervo da União, mas as receitas decorrentes de sua operação pertencem, mesmo que sem um termo jurídico que determine isso, à INFRAERO.

Conforme já comentado, a INFRAERO necessita avaliar a qualidade de seus investimentos. Para tanto, considerar-se-á que essa empresa detém como ativo, o direito de obter os benefícios futuros da operação da infra-estrutura aeroportuária por ela criada ou a ela cedida para administrar e/ou explorar. Pois, a qualidade do investimento não dependerá do fato de que ele seja de propriedade ou não da INFRAERO. Enfim, o tratamento desses investimentos como um ativo é fundamental para que seja feita sua correta avaliação.

A questão que se coloca agora é a mensuração desse ativo. Qual o valor deve ser atribuído aos investimentos? Ou melhor: Quanto valem esses investimentos para a INFRAERO?

A esse respeito, pesquisadores da Teoria Contábil trazem formas de avaliação de ativos tais como:

a) custo histórico: é utilizado na contabilização dos ativos por estar enquadrado dentro dos princípios contábeis. Trata-se do registro pelo valor de aquisição do ativo;

b) custo histórico corrigido pela variação do poder aquisitivo da moeda: é o valor de aquisição atualizado por índices de inflação;

c) custo corrente (ou de reposição): é o valor que custaria o ativo caso fosse necessário realizar sua reposição;

d) valores de liquidação: presume a venda forçada, tanto para clientes normais a preços extremamente reduzidos, como para outras firmas, bem abaixo do custo;

e) valores descontados: soma dos valores dos fluxos futuros de caixa descontados a determinada taxa de juros.

No caso de investimentos em aeroportos, o conceito de custo histórico poderia ser utilizado para registro no ativo diferido da empresa, sendo amortizado no período de 20 anos ou no que 
a lei permitir. Esta contabilização teria o objetivo de obter indenizações da União caso determinado aeroporto fosse retirado da administração da INFRAERO. Porém, conforme explicitado, não caberá a este trabalho o aprofundamento no âmbito dessa questão.

Para obter uma avaliação capaz de fornecer informação para uma melhor tomada de decisões de investimentos, será aprofundado o $5^{\circ}$ conceito apresentado: Valores descontados.

A exemplificação a seguir está baseada na metodologia aplicada por Iudícibus (2000) para avaliação de ativos.

Suponha-se que determinada empresa adquira um equipamento que tenha uma vida útil de três anos e que seja capaz de gerar receitas líquidas anuais no valor R $\$ 100.000$ e que tenha um custo operacional anual de R $\$ 10.000$. Considere-se ainda um retorno desejado de $20 \%$ ao ano e que esta máquina poderá ser vendida ao final de sua vida útil pelo valor de $\mathrm{R} \$ 20.000$. Segundo Iudícibus o valor desse equipamento pode assim ser calculado:

\section{Valor Atual das Receitas Liquidas Futuras}

$\mathrm{VARLF}=\mathrm{R} \$ 90.000 /(1,20)+\mathrm{R} \$ 90.000 /(1,20)^{2}+\mathrm{R} \$ 90.000 /(1,20)^{3}$

$\mathrm{VARLF}=\mathrm{R} \$ 189.583,33$

\section{Valor Atual do Valor Residual}

$\mathrm{VAVR}=\mathrm{R} \$ 20.000 /(1,20)^{3}$

$\mathrm{VAVR}=\mathrm{R} \$ 11.574,07$

\section{Valor Atual do Equipamento}

$\mathrm{VAE}=\mathrm{VARLF}+\mathrm{VAVR}=\mathrm{R} \$ 189.583,33+\mathrm{R} \$ 11.574,07=\mathrm{R} \$ 201.157,40$

Comparando-se este valor encontrado com o custo inicial do equipamento pode-se decidir quanto à sua aquisição ou não. Ou seja, para que se tenha o retorno mínimo esperado de $20 \%$ ao ano o equipamento não poderia custar mais de $\mathrm{R} \$ 201.157,40$.

O problema que aqui se coloca é a seleção de uma taxa apropriada de desconto. Essa taxa deve representar um risco equivalente ao do investimento considerado. Porém, esse problema 
foi tratado anteriormente. A taxa em questão também pode ser a chamada de Custo de Oportunidade.

Esta forma de avaliação de ativos é considerada um dos mais complexos assuntos em Contabilidade. Trata-se de uma das perspectivas da definição do termo Goodwill.

"Goodwill é o valor atual dos lucros futuros esperados, descontados por seus custos de oportunidade" (IUDÍCIBUS, 2000, p. 211).

O Custo de Oportunidade em questão se trata do Custo de Capital. Isso porque o custo de capital apresenta a taxa de remuneração que possua risco equivalente ao risco do negócio. Além disso, o Custo de Capital retrata a necessidade do negócio com vistas à autosustentabilidade do mesmo, conforme revisado no capítulo que se refere a este último conceito.

Sob a perspectiva da técnica do orçamento de capital, o goodwill seria o conceito equivalente ao Valor Presente Líquido (VPL). O goodwill seria a diferença entre o valor presente dos fluxos de caixa gerados pelo empreendimento e o valor do investimento para que fosse possível a geração de tais fluxos.

O goodwill calculado com base na taxa de desconto advinda do custo de capital será a medida capaz de mensurar a auto-sustentabilidade do investimento mantendo o valor do capital investido. Por conseguinte, esta medida será calculada pela diferença entra soma dos fluxos de caixa futuros de um investimento trazidos a valor presente por meio da taxa de remuneração exigida pelo capital e o valor desembolsado para a realização do mesmo investimento.

\subsection{OUTROS BENEFÍCIOS DE UM INVESTIMENTO}

Além das medidas internas das empresas definidas nas análises de desempenho tais como as revistas no presente trabalho, existem os impactos sofridos pelo ambiente externo. A consideração desses impactos é extremamente importante no caso de empresas com natureza de serviço público como a INFRAERO. Essa empresa está inserida num contexto de desenvolvimento e suas metas estão pautadas em objetivos advindos da política de desenvolvimento do Brasil. 
A realização de bons resultados econômicos e financeiros não é garantia do cumprimento de sua missão. A razão da existência da INFRAERO é o desenvolvimento da infraestrutura aeroportuária e aeronáutica com vistas ao desenvolvimento da nação. Sendo assim, os impactos de seus investimentos sobre a sociedade são tão relevantes quanto seus resultados financeiros.

Para Da Silva (1990, p. 346), "a avaliação do impacto econômico deve levar em conta os efeitos diretos e indiretos do aeroporto para a sociedade". Um sistema aeroportuário gera aumento dos negócios, aumento de empregos e conseqüentemente a renda, proporciona infraestrutura urbana e uma série de benefícios sociais. Enfim, aeroportos geram desenvolvimento local, regional e nacional.

A avaliação de todos os benefícios do investimento em infra-estrutura aeroportuária é capaz de proporcionar outro ponto de vista acerca da realização do mesmo. Para a INFRAERO, um investimento pode ser comprovadamente oneroso aos seus cofres, enquanto para o desenvolvimento regional, o mesmo investimento é visto como altamente lucrativo.

O reconhecimento de outros benefícios, além dos impactos sobre as finanças da empresa, torna-se relevante para a escolha de um entre dois ou mais investimentos. Além disso, a definição desses benefícios é um importante instrumento na obtenção de recursos junto ao governo ou prefeitura do local recebedor de investimento.

A dificuldade está na mensuração desses benefícios em unidades monetárias. Contudo, existem estudos de mensuração desses benefícios como os demonstrados por Da Silva (1990) em sua obra Aeroportos e Desenvolvimento nos quais são apresentados estudos de caso dos aeroportos de Faro, Ile de France e de Salvador.

Algumas variáveis que podem ser analisadas nesse tipo de estudo são:

- Geração de empregos;

- Integração nacional;

- Segurança nacional;

- Escoamento de produção; 
- Urbanização.

Definidas as prioridades do desenvolvimento em questão, pode-se decidir entre os projetos disponíveis analisando qual deles proporciona mais incremento na variável prioritária. Se na política de desenvolvimento for definida como prioridade a geração de empregos, selecionase o projeto que maior número de empregos pode gerar.

No entanto, utilizando este modelo decisório, corre-se o risco de incorrer em resultados predatórios ao investidor, fazendo com que sua capacidade de realizar outros investimentos diminua. No caso da INFRAERO, os resultados negativos decorrentes de vários projetos selecionados a partir desse modelo levariam, naturalmente, ao fim da empresa, caso não haja aporte de recursos do Governo.

Portanto, a identificação e avaliação dos benefícios sociais de um projeto de investimento em infra-estrutura aeroportuária podem contribuir para a seleção dos projetos que serão realizados. Antes, se faz necessária a avaliação econômico-financeira dos mesmos de modo a garantir a auto-sustentabilidade da INFRAERO.

Contudo, tratamento diferenciado deve ser dado a certo grupo de investimentos que não devem ter como requisito o critério da rentabilidade. Dentre esses investimentos, pode ser citado como exemplo, os efetuados em segurança (AVSEC). Tais investimentos devem ser avaliados separadamente para que não sejam rejeitados por não apresentarem rentabilidade mínima.

Em outras palavras, é preciso que se tire proveito financeiro dos aeroportos sem relegar a um segundo plano a natureza de serviço público da criação/manutenção de infra-estrutura aeroportuária. $\mathrm{O}$ equilíbrio entre essas duas frentes deve ser buscado, haja vista a necessidade de que os investimentos em aeroportos sejam rentáveis como qualquer outro.

Portanto, a tomada de decisão de investimentos não deve ser unicamente pautada na avaliação da rentabilidade do empreendimento. Deve-se buscar a rentabilidade de investimentos de caráter não obrigatório para compensar os investimentos obrigatórios, tais como manutenção de infra-estrutura existente, investimentos de segurança e outros. 


\subsection{MODEL DE ADMINISTRAÇÃO DA INFRAERO}

O pressuposto do desenvolvimento do modelo de avaliação da auto-sustentabilidade da INFRAERO diante da realização de investimentos em infra-estrutura aeroportuária é o modelo de administração aplicado na rede INFRAERO. Este modelo de administração é baseado no equilíbrio de resultados. Ou seja, a geração de resultados positivos excedentes em parte dos aeroportos é que garante a operação dos aeroportos que geram resultados negativos.

A Diretoria Financeira da INFRAERO aponta que 30 dos 67 aeroportos são superavitários. A operação dos demais aeroportos é subsidiada pelo resultado financeiro excedente dos aeroportos mais ricos. Dessa forma, a INFRAERO possui capacidade de garantir a distribuição de riquezas na rede de aeroportos administrados. Por conseguinte, aeroportos que possuem função estratégica para o desenvolvimento do país podem ter sua operação garantida mesmo que apresentem resultados financeiros negativos ou sejam considerados inviáveis do ponto de vista econômico-financeiro.

As tabelas a seguir demonstram o resultado econômico das dependências lucrativas e deficitárias da INFRAERO, entre os anos de 2001 e 2006, antes da realização de investimentos considerados como despesas. Os dados foram apurados até o mês de novembro de 2006, em virtude de não estarem disponíveis os dados do fechamento contábil do referido exercício social. 
Tabela 3.1 - Aeroportos INFRAERO - Maiores Lucros Acumulados Entre os Anos de 2001 e 2006

\begin{tabular}{|c|c|}
\hline AEROPORTOS OU UNIDADES & $\begin{array}{l}\text { RESULTADO } \\
\text { FINANCEIRO }\end{array}$ \\
\hline $\begin{array}{l}057 \text { AEROP. INT. DE SÃO PAULO/GUARULHOS-GOV. } \\
\text { ANDRÉ F. M }\end{array}$ & 1.866.696.212,49 \\
\hline 026 AEROP. INT. DE CAMPINAS/VIRACOPOS & $678.171 .208,57$ \\
\hline $\begin{array}{l}061 \text { AEROP. INT. DO RIO DE JANEIRO/GALEÃO-ANTONIO } \\
\text { CARLO }\end{array}$ & $294.580 .640,99$ \\
\hline 024 AEROP. INT. DE SÃO PAULO/CONGONHAS & $273.516 .202,08$ \\
\hline 025 AEROP. INT. DE MANAUS/EDUARDO GOMES & $148.800 .288,33$ \\
\hline 007 AEROP. INT. DE CURITIBA/AFONSO PENA & 129.377.556,11 \\
\hline $\begin{array}{l}015 \text { AEROP. INT. DE SALVADOR/DEP. LUIIS EDUARDO } \\
\text { MAGALHÃE }\end{array}$ & $96.738 .237,54$ \\
\hline 005 AEROP. DA PAMPULHA ( BELO HORIZONTE) & $77.802 .752,94$ \\
\hline 013 AEROP. INT. DE PORTO ALEGRE/SALGADO FILHO & $75.313 .242,53$ \\
\hline 062 AEROP. SANTOS DUMONT (RIO DE JANEIRO) & $75.185 .872,29$ \\
\hline 023 AEROP. GOIABEIRAS (VITÓRIA) & $65.851 .901,92$ \\
\hline 010 AEROP. INT. DE FORTALEZA/PINTO MARTINS & $58.447 .527,31$ \\
\hline $\begin{array}{l}002 \text { AEROP. INT. DE BRASÍLIA/PRESIDENTE JUSCELINO } \\
\text { KUBIT }\end{array}$ & $53.042 .921,23$ \\
\hline 011 AEROP. DE GOIÂNIA/SANTA GENOVEVA & $41.414 .570,09$ \\
\hline 072 GNA RIBEIRÃO PRETO & $27.680 .208,71$ \\
\hline 008 AEROP. INT. DE FLORIANÓPOLIS/HERCÍLIO LUZ & $25.319 .050,38$ \\
\hline 028 AEROP. INT. DE NATAL/AUGUSTO SEVERO & $24.521 .491,93$ \\
\hline 086 GNA - BOM JESUS DA LAPA & $17.128 .870,85$ \\
\hline $\begin{array}{l}\text { 034 AEROP. DE NAVEGANTES/MINISTRO VICTOR } \\
\text { KONDER }\end{array}$ & $15.323 .512,19$ \\
\hline 080 GNA - CARAVELAS & $15.311 .892,65$ \\
\hline
\end{tabular}


Tabela 3.2 - Aeroportos INFRAERO - Maiores Prejuízos Acumulados Entre os Anos de 2001 e 2006

\begin{tabular}{|c|c|}
\hline AEROPORTOS OU UNIDADES & $\begin{array}{l}\text { RESULTADO } \\
\text { FINANCEIRO }\end{array}$ \\
\hline 001 SEDE - ADMINISTRAÇÃO CENTRAL & $(471.067 .266,76)$ \\
\hline 004 AEROP. INT. DE BELÉM/VAL-DE-CÃES & $(62.655 .678,48)$ \\
\hline $\begin{array}{l}014 \text { AEROP. INT. DE RECIFE/GUARARAPES-GILBERTO } \\
\text { FREYRE }\end{array}$ & $(36.738 .857,13)$ \\
\hline $\begin{array}{l}149 \text { AEROP. DE SÃO JOSÉ DOS CAMPOS - PROF. URBANO } \\
\text { ERNES }\end{array}$ & $(15.526 .931,57)$ \\
\hline 029 AEROP. INT. DE RIO BRANCO/PRESIDENTE MÉDICI & $(11.699 .809,11)$ \\
\hline 031 AEROP. INT. DE MACAPÁ & $(10.115 .713,06)$ \\
\hline 040 AEROP. INT. DE SANTARÉM & $(10.002 .334,38)$ \\
\hline 018 AEROP. INT. DE CORUMBÁ & $(8.454 .979,93)$ \\
\hline 006 AEROP. INT. DE BOA VISTA & $(7.661 .337,11)$ \\
\hline 043 AEROP. INT. DE TABATINGA & $(7.540 .132,47)$ \\
\hline 042 AEROP. INT. DE CRUZEIRO DO SUL & $(6.156 .163,22)$ \\
\hline 047 AEROP. DE MARABÁ & $(4.438 .961,08)$ \\
\hline 152 AEROP. DE PALMAS/TOCANTINS & $(4.066 .026,11)$ \\
\hline 041 AEROP. DE ALTAMIRA & $(4.023 .851,11)$ \\
\hline 016 AEROP. SANTA MARIA (ARACAJU) & $(3.728 .899,62)$ \\
\hline 052 AEROP. INT. DE URUGUAIANA/RUBEM BERTA & $(3.554 .094,04)$ \\
\hline $\begin{array}{l}046 \text { AEROP. DE IMPERATRIZ - PREFEITO RENATO } \\
\text { MOREIRA }\end{array}$ & $(3.471 .928,68)$ \\
\hline $\begin{array}{l}030 \text { AEROP. DE PORTO VELHO/GOV. JORGE TEIXEIRA DE } \\
\text { OLIVE }\end{array}$ & $(3.094 .348,09)$ \\
\hline 044 AEROP. DE TEFÉ & $(2.913 .622,86)$ \\
\hline 048 AEROP. INT. DE PONTA PORÃ & $(2.059 .524,95)$ \\
\hline
\end{tabular}


Os resultados financeiros foram obtidos a partir do resultado econômico somando-se as despesas não financeiras como a depreciação e a provisão para créditos de liquidação duvidosa.

A soma dos resultados de todas as unidades superavitárias atingiu o montante de $\mathrm{R} \$ 4,29$ bilhões entre os anos de 2001 e 2006. No entanto, os resultados negativos das unidades deficitárias, no valor de R\$ 690 milhões, fizeram com que a INFRAERO obtivesse resultado financeiro de $\mathrm{R} \$$ 3,6 bilhões antes da realização de investimentos. Este fato ilustra de forma objetiva o equilíbrio de resultados gerado pelo modelo de administração aplicado para a gestão dos empreendimentos da INFRAERO.

Contudo, este equilíbrio não pode ser considerado unicamente como resultante de eficiente gestão de investimentos em infra-estrutura. A afirmação de que os investimentos realizados são auto-sustentáveis somente poderia ser tomada como verdade se a INFRAERO houvesse realizado desembolso para obtenção de toda infra-estrutura por ela administrada e explorada.

Isto não ocorreu, visto que inúmeros aeroportos foram absorvidos pela rede sem realização de qualquer desembolso. Portanto, parte dos resultados positivos dos aeroportos absorvidos poderia ser considerado, na pratica, doação realizada pela União à INFRAERO, pois esta empresa passou a administrar estes aeroportos sem a realização de qualquer investimento. Por conseguinte, pode-se observar que o equilíbrio de resultados apresentado decorre também da absorção de aeroportos sem realização de desembolsos e não somente da gestão de investimentos.

A observação dos resultados passados permite verificar que os mesmos estão maquiados por esse fato. Porém, a INFRAERO realiza investimentos em manutenção de infra-estrutura aeroportuária para tornar possível a continuidade da operação dos aeroportos absorvidos.

Muitas vezes torna-se necessária a construção de um novo aeroporto, como no caso do Aeroporto Goiabeira, em Vitória-ES. Chegará o momento em que os resultados positivos advindos da absorção de aeroportos sem realização de desembolsos deixarão de existir. Nesse momento, somente os resultados decorrentes de investimentos realizados pela INFRAERO serão gerados. 
Daí surge a necessidade de previsão de resultados para que seja verificado o potencial de auto-sustentabilidade da INFRAERO mediante a realização de investimentos. Em outras palavras, a INFRAERO precisa investir em empreendimentos com potencial de geração de resultados positivos de modo a garantir o subsídio dos resultados de empreendimentos deficitários. Há, portanto, que se tomar o cuidado de não investir a maior parte dos recursos em empreendimentos deficitários.

Por oportuno, uma ferramenta que seja capaz de avaliar a auto-sustentabilidade se faz necessária ao processo de tomada de decisão para escolha de empreendimentos a serem realizados.

Em muitos dos projetos analisados existe a previsão de que sejam deficitários. Os investimentos nesses projetos podem ser justificados por outros fatores, tais como política de desenvolvimento regional, integração e segurança nacional e outros apresentados no capítulo que trata de outros benefícios de um investimento.

Também é relevante conhecer a formação do resultado financeiro da INFRAERO. Seus resultados são formados pelos seguintes elementos de Receita e Despesas:

\subsubsection{Receitas}

- Pouso e Permanência

Valores que remuneram os custos dos serviços e das facilidades proporcionadas às operações de pouso e permanência de aeronaves no pátio.

- Embarque

Valores devidos pelos passageiros e repassados pelas empresas aéreas, com a finalidade de remunerar a prestação de serviços, instalações e facilidades existentes nos terminais de passageiros

- Armazenagem e Capatazia

Valores que remuneram os gastos dos serviços e facilidades disponíveis aos usuários dos terminais de carga aérea, tais como: armazenamento, guarda, controle, movimentação e manuseio da carga no recinto do Terminal de Cargas (TECA). 
- Navegação Aérea

Valores que remuneram serviços e facilidades disponíveis aos usuários destinados a apoiar e tornar segura a navegação aérea

- Comerciais

São receitas correspondentes aos serviços prestados através das diversas atividades da empresa ligadas à administração aeroportuária e as vendas de mercadorias, quando for o caso

- Financeiras

São as receitas oriundas das diversas operações financeiras da empresa.

A seguir pode-se verificar a participação das receitas no faturamento da INFRAERO.

Gráfico 3.1 - Participação das Receitas no Faturamento da INFRAERO Entre os Anos de 2001 e 2006

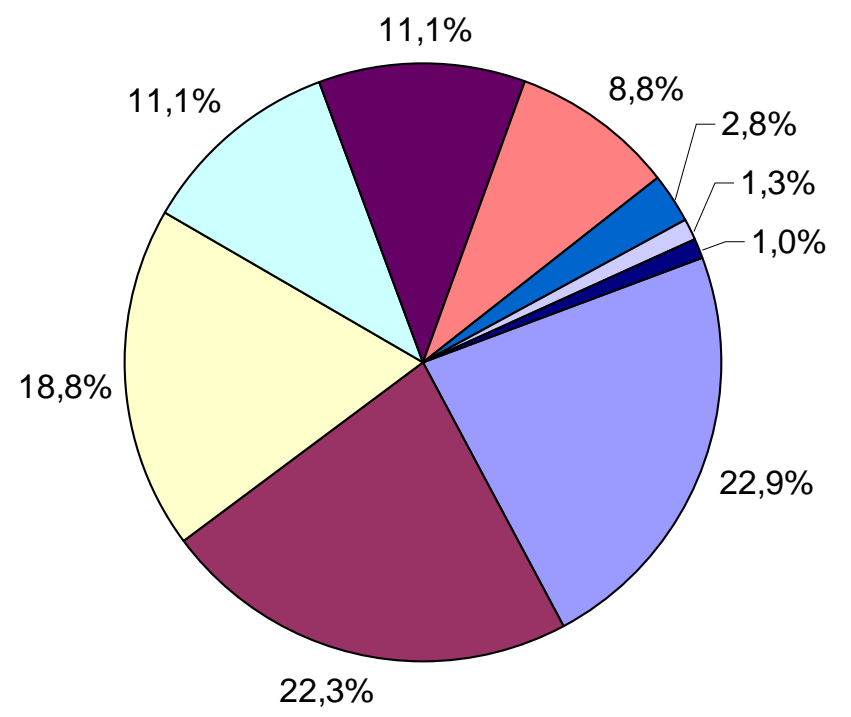

$\square$ Armazenagem e Capatazia

$\square$ Embarque

- Pouso

$\square$ Outros Serviços

- Permanência

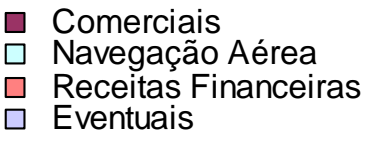

$\square$ Navegação Aérea

$\square$ Eventuais 


\subsubsection{Despesas}

- Pessoal

Despesas com pessoal próprio da INFRAERO. Composto pelos salários, gratificações, adicionais estabelecidos na legislação trabalhista, ajudas de custo, horas extras, etc.

- Encargos com Pessoal

Despesas com encargos diretos e indiretos com pessoal próprio da INFRAERO e com pessoal requisitado.

- Materiais de Consumo

Despesas com material utilizado ou consumido nas atividades de apoio administrativo, operação, manutenção e conservação de bens e instalações.

- Serviços Contratados e Locações

Serviços especializados efetuados por empresas e/ou profissionais autônomos, mediante contratos. São os serviços auxiliares, necessários à Administração para o desempenho de suas atribuições, cuja interrupção possa comprometer a continuidade de suas atividades e cuja contração deva estender-se por mais de um exercício financeiro.

- Utilidades e Serviços Públicos

Despesas referentes ao consumo de serviços e utilidades fornecidos pelas concessionárias de serviços, indispensáveis ao desenvolvimento das atividades da empresa, tais como Água e Esgoto, Energia Elétrica, Remoção de Lixo, etc.

- Despesas Gerais

Despesas diversas e necessárias para a gestão da empresa, que se constituem de várias atividades que beneficiam os negócios da empresa, tais como Diárias de Viagens, Descontos Concedidos, Fretes e Carretos, Publicações Oficiais, Reprografia, Seguros em Geral, Taxa de Administração do Sistema Unificado de Cobrança de Tarifas Aeroportuárias - SUCOTAP.

- Financeiras 
Todas as despesas bancárias, de correção monetária de tributos, juros, multas, etc.

A seguir pode-se verificar a participação de cada despesa nos gastos totais.

Gráfico 3.2 - Participação das Despesas nos Gastos Totais Entre os Anos de 2001 e 2006

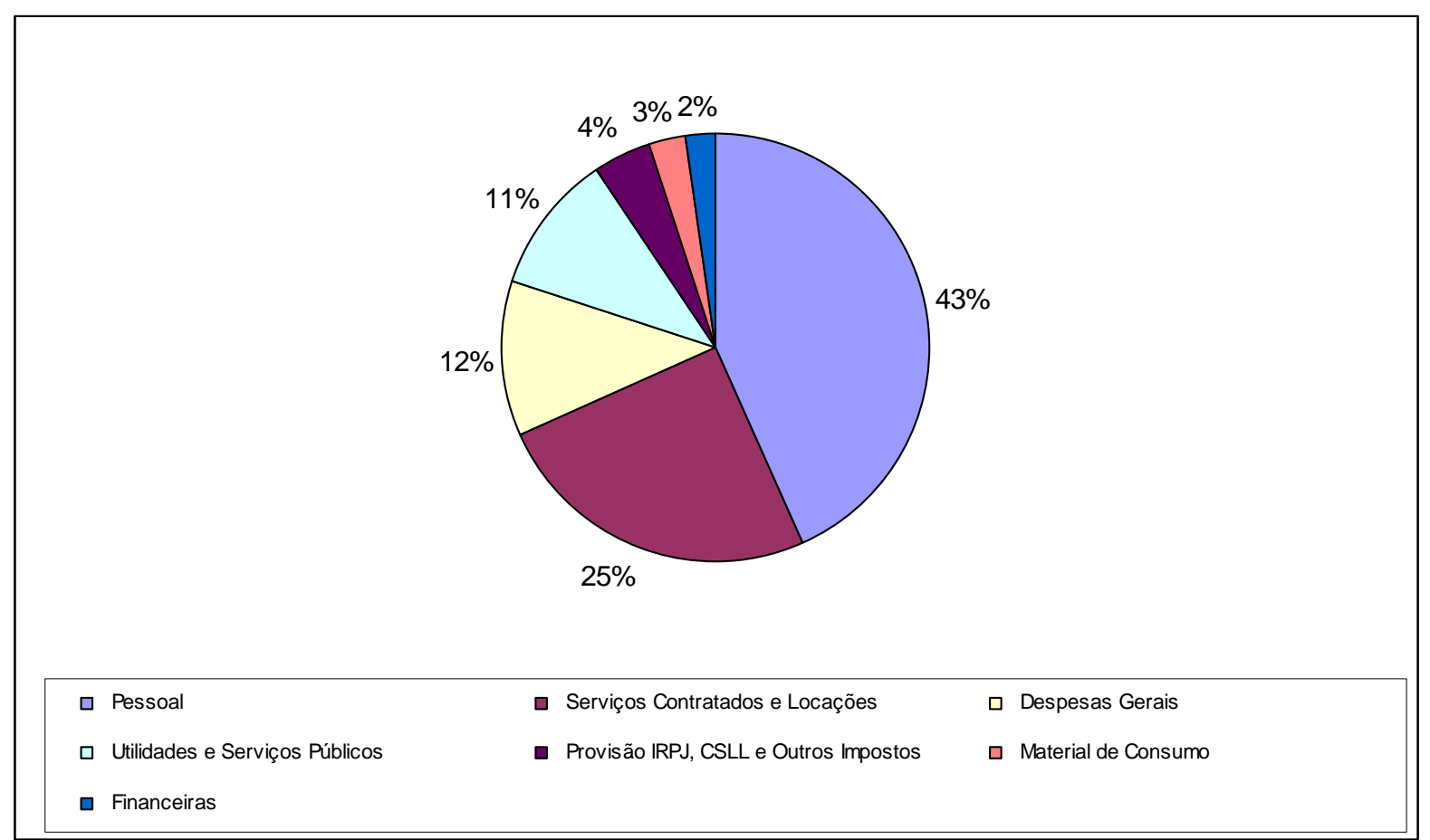

\subsection{AUTO-SUSTENTABILIDADE DA INFRAERO}

Apresenta-se daqui por diante a síntese da linha de raciocínio para a definição do que seja um indicador de auto-sustentabilidade da INFRAERO.

O conceito de auto-sustentabilidade está definido na revisão bibliográfica como "a necessidade que as organizações têm de gerar recursos próprios para financiar suas atividades" (ARAÚJO, 2005). Sabe-se que a geração de recursos depende do sucesso dos investimentos realizados no negócio. Logo, se o valor aplicado for superado pelo valor dos resultados, pode-se dizer que o empreendimento se sustenta do ponto de vista econômico.

Todavia, somente gerar recursos que garantam a rentabilidade mínima do negócio ao longo de sua vida útil não é garantia de que ele se sustente. Este fator é apenas um indicador de que a empresa possui condições de ser auto-sustentável. 
A auto-sustentabilidade depende também da constância de liquidez da empresa. Pois, a INFRAERO pode apresentar VPL descontado pelo Custo de Capital positivo e ainda assim não se sustentar em virtude do longo prazo de retorno em seus investimentos. Ou seja, é possível que não apresente capacidade de gerar recursos suficientes para realizar os pagamentos dos primeiros períodos de um investimento. Isso pode ocorrer, visto que uma das limitações da técnica do VPL é a falta de capacidade de verificação da liquidez dos projetos ao longo de sua duração.

No entanto, o modelo a ser desenvolvido com base nesse conceito não perde sua relevância, visto que para ser sustentável financeiramente, o empreendimento necessita apresentar-se viável do ponto de vista econômico. Ou seja, precisa apresentar características que permitam conduzi-lo à sua continuidade.

Trata-se do primeiro passo em direção à verificação da afirmação de que a INFRAERO seja auto-sustentável. Em outras palavras, a criação do modelo permitirá dizer se a INFRAERO não é auto-sustentável, mas não será capaz de afirmar que ela de fato o é.

Então, para reconhecer a falta de auto-sustentabilidade de um negócio faz-se necessário conhecer as seguintes variáveis:

- Valor atual dos desembolsos realizados a título de investimentos;

- Valor dos resultados financeiros (fluxos de caixa líquidos) até o fím da vida útil do empreendimento;

- Taxa de desconto para aplicação sobre os resultados financeiros futuros.

Definiu-se que a taxa de desconto apropriada para o desconto dos fluxos de caixa é a taxa mínima de retorno dos acionistas ou Custo de Capital. Porém, o ideal é que cada projeto de investimento tenha a sua taxa de Custo de Capital fundamentada no risco atrelado aos fluxos de caixa. Ou seja, seria necessário avaliar o Custo de Capital de cada empreendimento por meio da metodologia de Precificação de Ativos (CAPM).

Para efeito do desenvolvimento do modelo de avaliação de auto-sustentabilidade proposto, será considerado como custo de capital dos projetos de investimento a mesma taxa de custo de capital calculada pela INFRAERO como sendo sua. Este procedimento baseia-se no fato 
de que seria despendida atenção excessiva e inviável ao cálculo do custo de capital de todos os projetos.

Todavia, ressalta-se que a utilização mais perfeita do modelo depende da realização do estudo de custo de capital individual dos projetos de investimento.

Com base nos conceitos revistos no decorrer do trabalho, pode-se, então, descrever o modelo de avaliação de auto-sustentabilidade como sendo a diferença entre a soma dos resultados financeiros futuros dos aeroportos, descontados a valor presente pela taxa de remuneração do capital (custo de capital), e o valor atual desembolsado a título de investimento.

Valor dos Resultados Financeiros Futuros Descontados pela Taxa do Custo de Capital ( - ) Valor Atual dos Investimentos

( = ) Valor de Auto-Sustentabilidade

Essa diferença precisa ser no mínimo nula para que a INFRAERO possa ser considerada auto-sustentável. Caso seja positiva, a empresa apresentará um excedente de valor de sustentabilidade a ser utilizado em outros empreendimentos. Do contrário, a INFRAERO estará comprometendo seus recursos em investimentos que destroem valor financeiro em sua maioria, tendo como conseqüência a necessidade de repasses da União para realização de novos investimentos.

O ponto chave deste cálculo está relacionado ao modelo de administração de aeroportos da INFRAERO. A proposta não é calcular o valor de auto-sustentabilidade de cada investimento separadamente, mas de realizar o cálculo no âmbito de todos os aeroportos administrados.

Isso se faz necessário para que investimentos em aeroportos superavitários possam dar subsídios aos investimentos em aeroportos deficitários. O objetivo não é avaliar cada investimento separadamente, mas avaliar os impactos da política de investimentos que vem sendo realizada, na auto-sustentabilidade da rede INFRAERO.

Para tanto, há que se considerar a política de absorção de aeroportos. Esta absorção pode ser danosa ao resultado financeiro da empresa caso o aeroporto em questão apresente sucessivos resultados negativos e projeções nada agradáveis do ponto de vista financeiro. A absorção deve ser considerada como um investimento de valor zero. Daí deve-se proceder ao cálculo 
da auto-sustentabilidade do aeroporto e somá-lo ao valor da auto-sustentabilidade de outros aeroportos.

Como é devida a consideração da absorção de aeroportos deficitários, a absorção de aeroportos superavitários também deve ser igualmente considerada. $\mathrm{O}$ valor de investimento zero e sucessivos resultados positivos projetados gerarão goodwill positivo. Isso fará com que a INFRAERO tenha folga de resultado para realização de outros investimentos que poderão até mesmo apresentar resultados negativos, porém gerando benefícios sociais previstos na política de desenvolvimento do Governo Federal.

\subsection{MENSURAÇÃO DOS FLUXOS DE CAIXA}

Um problema que se coloca diz respeito à mensuração dos fluxos de caixa futuros de todos os aeroportos administrados pela INFRAERO e que dela receberam investimentos. A mensuração desses fluxos de caixa depende de um bom estudo de previsão de demanda de número de operações, passageiros embarcados, concessões de áreas, despesas operacionais e outros desembolsos.

Este problema pode ser equacionado com o desenvolvimento de projeções de demonstrações financeiras baseadas em diversas variáveis que impactam nos resultados financeiros. Porém, este trabalho não entrará no mérito dessa questão, visto que não se trata de requisito para o desenvolvimento do modelo proposto. Considerar-se-á a mensuração dos fluxos de caixa como uma etapa posterior ao desenvolvimento do modelo.

Outro problema que poderia surgir é a associação dos resultados a serem alcançados com os investimentos realizados. Ou seja, poderia existir a necessidade de identificar o investimento que dá origem a cada variação no fluxo de caixa. Por conseguinte, somente o fluxo de caixa incremental dos projetos de investimentos poderia ser considerado para efeito do cálculo de goodwill.

O fluxo de caixa incremental poderia ser obtido pela diferença entre o valor do fluxo de caixa previsto com a realização do investimento e o previsto sem a realização desse investimento. Ou seja, somente seria considerado o fluxo de caixa gerado pelo investimento em análise. 
Mas esta perspectiva somente seria necessária para a avaliação individual de um investimento ou de um grupo de investimentos.

Para que esta perspectiva possa ser desprezada, serão considerados todos os aeroportos e unidades como investimentos realizados, mesmo os absorvidos sem realização de desembolsos conforme já explicitado. Assim, todos os fluxos gerados no âmbito da INFRAERO poderão ser considerados para efeito do cálculo do goodwill ou valor de autosustentabilidade com base no modelo.

\subsection{A DEFINIÇÃO DO VALOR DO CUSTO DE CAPITAL}

A metodologia utilizada para calcular o custo de capital da INFRAERO é a Precificação de Ativos (CAPM). Com base em uma série de informações relativas ao ambiente interno e externo da empresa, tais como as relativas ao risco do negócio.

O CAPM (“Capital Asset Pricing Model”) trata-se de um modelo de geração de retornos.

Como o custo de capital se trata do retorno mínimo esperado pelos investidores para aplicação de determinado recurso, o CAPM pode ser utilizado para cálculo desse retorno esperado.

O cálculo do custo de capital por meio desse método é disposto da seguinte forma:

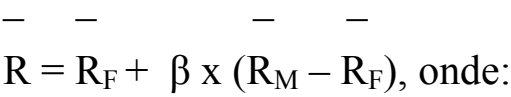

R: Retorno Esperado;

$\mathrm{R}_{\mathrm{F}}$ : Taxa livre de risco;

$\mathrm{R}_{\mathrm{M}}$ : Retorno esperado da carteira de mercado

$\mathrm{R}_{\mathrm{M}}-\mathrm{R}_{\mathrm{F}}$ : Diferença entre o retorno esperado da carteira de Mercado e a taxa livre de risco;

$\beta$ : O coeficiente beta da empresa. 
A utilização do custo de capital da empresa para trazer os fluxos futuros de todos os novos projetos a valor presente não é a forma mais correta de cálculo, haja vista as conseqüências danosas que esse método pode trazer. Contudo, pode-se considerar que o custo de capital da empresa é o que mais se aproxima do custo de capital de seus projetos, haja vista a similaridade entre os negócios dos projetos e os negócios da empresa.

O custo de capital da INFRAERO, definido no ano de 2006, é de 9,72\% ao ano. Esta é a taxa utilizada pela INFRAERO quando da avaliação e análise de novos projetos de investimentos.

A complexidade do cálculo individual dessa taxa é um fator que contribui para que seja utilizada a taxa de custo de capital da empresa.

\subsection{VALOR DOS INVESTIMENTOS}

Conhecer o valor desembolsado com recursos próprios na realização de todos os investimentos que geram recursos na INFRAERO é requisito para a aplicação do modelo proposto.

Deve ser dada especial atenção ao tratamento desses valores, uma vez que foram realizados em diferentes períodos. Cabe enfatizar que deve haver uma estimativa de atualização desses valores até a data de aplicação do modelo.

Vários critérios de atualização podem ser utilizados. Portanto, faz-se oportuno lembrar todos os conceitos de avaliação de ativos estudados na bibliografia para utilizar o que melhor traduzir o valor desses desembolsos.

O mais recomendável é método do custo histórico corrigido pela variação do poder aquisitivo da moeda, por traduzir o gasto efetuado considerando sua atualização com base em um índice de inflação apropriado ao investimento realizado.

Os índices da construção civil são os mais recomendáveis nos casos de investimentos que envolvem construção de aeroportos. Ou seja, de acordo com a característica de cada investimento são selecionados índices que melhor se adequarem à sua realidade. 
É relevante considerar que nem todas as dependências da INFRAERO terão ainda mais 20 períodos de vida útil. Portanto, do valor desembolsado atualizado deve-se subtrair os resultados já alcançados em períodos anteriores.

Por exemplo: Se o valor desembolsado atualizado de determinado investimento for $\mathrm{R} \$ 500$ milhões e já se passaram 10 anos de sua realização, deve-se subtrair do valor de R\$500 milhões o valor atual do resultado financeiro realizado nos períodos anteriores.

Esse procedimento tornará justo o valor de auto-sustentabilidade calculado.

\subsection{MODELO DE REALIZAÇÃO DO CÁLCULO DO VALOR DE AUTO- SUSTENTABILIDADE}

Considerar-se-á uma situação hipotética para a realização do cálculo do valor de autosustentabilidade.

Digamos que a INFRAERO possua apenas três aeroportos sob sua administração e que o seu custo de capital seja avaliado em $9,72 \%$ ao ano.

Os valores desembolsados atualizados e os resultados financeiros futuros previstos para os aeroportos da rede estão definidos conforme o que consta no próprio modelo.

Assim, pode-se proceder ao cálculo do valor de auto-sustentabilidade da forma disposta na Tabela3.3 
Tabela 3.3 - Modelo de Avaliação de Auto-Sustentabilidade

Valores em \$ 1 milhão

\begin{tabular}{|c|c|c|c|c|c|c|}
\hline & Fluxo de Caixa - Ano & 1 & 20,00 & 10,00 & $(20,00)$ & 10,00 \\
\hline & Fluxo de Caixa - Ano & 3 & 80,00 & 16,00 & $(60,00)$ & 36,00 \\
\hline & Fluxo de Caixa - Ano & 4 & 160,00 & 40,00 & $(40,00)$ & 160,00 \\
\hline & Fluxo de Caixa - Ano & 5 & 200,00 & 100,00 & $(20,00)$ & 280,00 \\
\hline & Fluxo de Caixa - Ano & 8 & 340,00 & 220,00 & 20,00 & 580,00 \\
\hline & Fluxo de Caixa - Ano & 9 & 340,00 & 240,00 & 60,00 & 640,00 \\
\hline & Fluxo de Caixa - Ano & 10 & 340,00 & 260,00 & 80,00 & 680,00 \\
\hline & Fluxo de Caixa - Ano & 11 & 340,00 & 260,00 & 100,00 & 700,00 \\
\hline & Fluxo de Caixa - Ano & 12 & 340,00 & 260,00 & 160,00 & 760,00 \\
\hline & Fluxo de Caixa - Ano & 13 & 360,00 & 240,00 & 160,00 & 760,00 \\
\hline & Fluxo de Caixa - Ano & 18 & 440,00 & - & - & 440,00 \\
\hline & Fluxo de Caixa - Ano & 19 & 420,00 & - & - & 420,00 \\
\hline & Fluxo de Caixa - Ano & 20 & 420,00 & - & - & 420,00 \\
\hline \multicolumn{3}{|l|}{ Custo de Capital } & \multicolumn{4}{|c|}{$9,72 \%$} \\
\hline Valor Presente dos Fluxos de Caixa (B) & & & $2.121,71$ & 942,29 & 159,82 & $3.223,82$ \\
\hline Valor de Auto-Sustentabilidade (B - A) & & & 121,71 & $(57,71)$ & 159,82 & 223,82 \\
\hline
\end{tabular}


Como se pode observar, o valor de auto-sustentabilidade é de $\$ 223,82$ milhões. Isso quer dizer que a empresa apresenta-se auto-sustentável no horizonte de tempo apresentado na situação hipotética.

Em observação ao modelo pode-se detectar qual aeroporto contribui mais negativamente com o Valor de Auto-Sustentabilidade de modo a empreender ações de mitigação de seus custos ou incremento de suas receitas. Por isso é relevante conhecer a composição desses elementos.

Podem-se aplicar nesse momento outras técnicas de gestão no sentido de melhorar o resultado financeiro de cada aeroporto.

$\mathrm{O}$ excesso de valor de auto-sustentabilidade permite que sejam realizados investimentos que gerem perda de valor financeiro de até $\$ 223,82$ milhões. Tais investimentos poderiam estar orientados a outros objetivos aquém das metas de resultado financeiro positivo. Neste caso, o investimento gerador de benefícios sociais poderia ser realizado. As perdas decorrentes desse investimento seriam compensadas pelo valor de auto-sustentabilidade existente.

A aplicação do modelo na previsibilidade de auto-sustentabilidade face à realização de outros investimentos é outra utilidade do mesmo. Pois, acrescentando-se as previsões de resultado dos novos projetos ao modelo pode-se ter idéia das metas de resultado a alcançar para manter a auto-sustentabilidade da INFRAERO.

Na prática, poderia ser incluída mais uma coluna de novos projetos após a coluna do Total. Nesta nova coluna poderiam ser estimados os valores mínimos a serem alcançados para a manutenção da auto-sustentabilidade da INFRAERO, ou ainda, poderiam ser incluídas as previsões de resultados financeiros dos novos projetos para verificar se os mesmos manteriam a auto-sustentabilidade econômica da INFRAERO.

A seguir apresenta-se a aplicação do modelo como definição de metas de resultados para manutenção de auto-sustentabilidade. 
Tabela 3.4 - Modelo de Avaliação de Auto-Sustentabilidade

\begin{tabular}{|c|c|c|c|c|c|c|c|}
\hline Aeroportos & & Aeroporto A & Aeroporto B & Aeroporto C & Total & $\begin{array}{c}\text { Novos } \\
\text { projetos }\end{array}$ & Total Geral \\
\hline Valores Investidos Atualizados (A) & & $2.000,00$ & $1.000,00$ & - & $3.000,00$ & 150,00 & $3.150,00$ \\
\hline Fluxo de Caixa - Ano & 1 & 20,00 & 10,00 & $(20,00)$ & 10,00 & $(11,79)$ & $(1,79)$ \\
\hline Fluxo de Caixa - Ano & 2 & 60,00 & 14,00 & $(70,00)$ & 4,00 & $(11,79)$ & $(7,79)$ \\
\hline Fluxo de Caixa - Ano & 3 & 80,00 & 16,00 & $(60,00)$ & 36,00 & $(11,79)$ & 24,21 \\
\hline Fluxo de Caixa - Ano & 4 & 160,00 & 40,00 & $(40,00)$ & 160,00 & $(11,79)$ & 148,21 \\
\hline Fluxo de Caixa - Ano & 5 & 200,00 & 100,00 & $(20,00)$ & 280,00 & $(11,79)$ & 268,21 \\
\hline Fluxo de Caixa - Ano & 6 & 320,00 & 160,00 & - & 480,00 & $(11,79)$ & 468,21 \\
\hline Fluxo de Caixa - Ano & 7 & 340,00 & 200,00 & - & 540,00 & $(11,79)$ & 528,21 \\
\hline Fluxo de Caixa - Ano & 8 & 340,00 & 220,00 & 20,00 & 580,00 & $(11,79)$ & 568,21 \\
\hline Fluxo de Caixa - Ano & 9 & 340,00 & 240,00 & 60,00 & 640,00 & $(11,79)$ & 628,21 \\
\hline Fluxo de Caixa - Ano & 10 & 340,00 & 260,00 & 80,00 & 680,00 & $(11,79)$ & 668,21 \\
\hline Fluxo de Caixa - Ano & 11 & 340,00 & 260,00 & 100,00 & 700,00 & $(11,79)$ & 688,21 \\
\hline Fluxo de Caixa - Ano & 12 & 340,00 & 260,00 & 160,00 & 760,00 & $(11,79)$ & 748,21 \\
\hline Fluxo de Caixa - Ano & 13 & 360,00 & 240,00 & 160,00 & 760,00 & $(11,79)$ & 748,21 \\
\hline Fluxo de Caixa - Ano & 14 & 380,00 & 220,00 & 160,00 & 760,00 & $(11,79)$ & 748,21 \\
\hline Fluxo de Caixa - Ano & 15 & 400,00 & - & 140,00 & 540,00 & $(11,79)$ & 528,21 \\
\hline Fluxo de Caixa - Ano & 16 & 420,00 & - & 120,00 & 540,00 & $(11,79)$ & 528,21 \\
\hline Fluxo de Caixa - Ano & 17 & 440,00 & - & 60,00 & 500,00 & $(11,79)$ & 488,21 \\
\hline Fluxo de Caixa - Ano & 18 & 440,00 & - & - & 440,00 & $(11,79)$ & 428,21 \\
\hline Fluxo de Caixa - Ano & 19 & 420,00 & - & - & 420,00 & $(11,79)$ & 408,21 \\
\hline Fluxo de Caixa - Ano & 20 & 420,00 & - & - & 420,00 & $(11,79)$ & 408,21 \\
\hline \multicolumn{2}{|l|}{ Custo de Capital } & \multicolumn{4}{|c|}{$9,72 \%$} & $15,00 \%$ & $15,00 \%$ \\
\hline \multicolumn{2}{|l|}{ Valor Presente dos Fluxos de Caixa (B) } & $2.121,71$ & 942,29 & 159,82 & $3.223,82$ & $(\mathrm{R} \$ 73,82)$ & $3.150,00$ \\
\hline \multicolumn{2}{|l|}{ Valor de Auto-Sustentabilidade (B - A) } & 121,71 & $(57,71)$ & 159,82 & 223,82 & $(223,82)$ & 0,00 \\
\hline
\end{tabular}


No exemplo acima, considerou-se que a empresa dispunha de \$150 milhões para a realização de investimentos. Com esse montante disponível e considerando-se a taxa de custo de capital dos projetos em 15\%, o resultado financeiro mínimo a ser alcançado em cada um dos 20 períodos de vida útil do projeto poderia ser negativo em $\$ 11,79$ milhões. Ou seja, o empreendimento poderia apresentar resultados negativos até o limite de \$11,79 mihões para manutenção da auto-sustentabilidade econômica.

Conforme já explicado, tendo em mãos a consolidação dos estudos de viabilidade de projetos de investimentos, as previsões reais de resultados financeiros dos novos projetos podem ser comparadas às metas de resultado encontradas no modelo.

Assim será possível verificar se os novos projetos determinam a falta de auto-sustentabilidade da INFRAERO no horizonte da vida útil de todos os investimentos.

Caso a soma dos valores encontrados nos totais de Valor de Auto-Sustentabilidade for menor que zero, pode-se afirmar que a INFRAERO não será auto-sustentável realizando tais investimentos.

Todavia, o fato de a referida soma ser maior que zero não é condição suficiente para afirmar que a INFRAERO será auto-sustentável no referido horizonte de tempo. Isso se deve ao fato de que a auto-sustentabilidade econômica verificada não é garantia de liquidez da empresa ao longo da vida útil dos empreendimentos.

A coluna Total Geral da Tabela 5 informa o resultado financeiro em cada período. Observa-se que nos primeiros períodos o resultado seria negativo. Ou seja, a empresa não teria recursos suficientes para seu sustento. Logo, pode-se confirmar que o valor zero de autosustentabilidade não é condição suficiente para determinar que a INFRAERO seja autosustentável. Mas, um valor de auto-sustentabilidade menor que zero é condição suficiente para determinar que a INFRAERO não seja auto-sustentável.

Portanto, o modelo demonstra capacidade de verificar a falta de auto-sustentabilidade do conjunto de empreendimentos do negócio da INFRAERO, mediante apresentação de estudo de viabilidade econômico-financeira dos mesmos. 
A Figura 3.1 traz a representação gráfica que sintetiza o Modelo de Avaliação de AutoSustentabilidade desenvolvido.

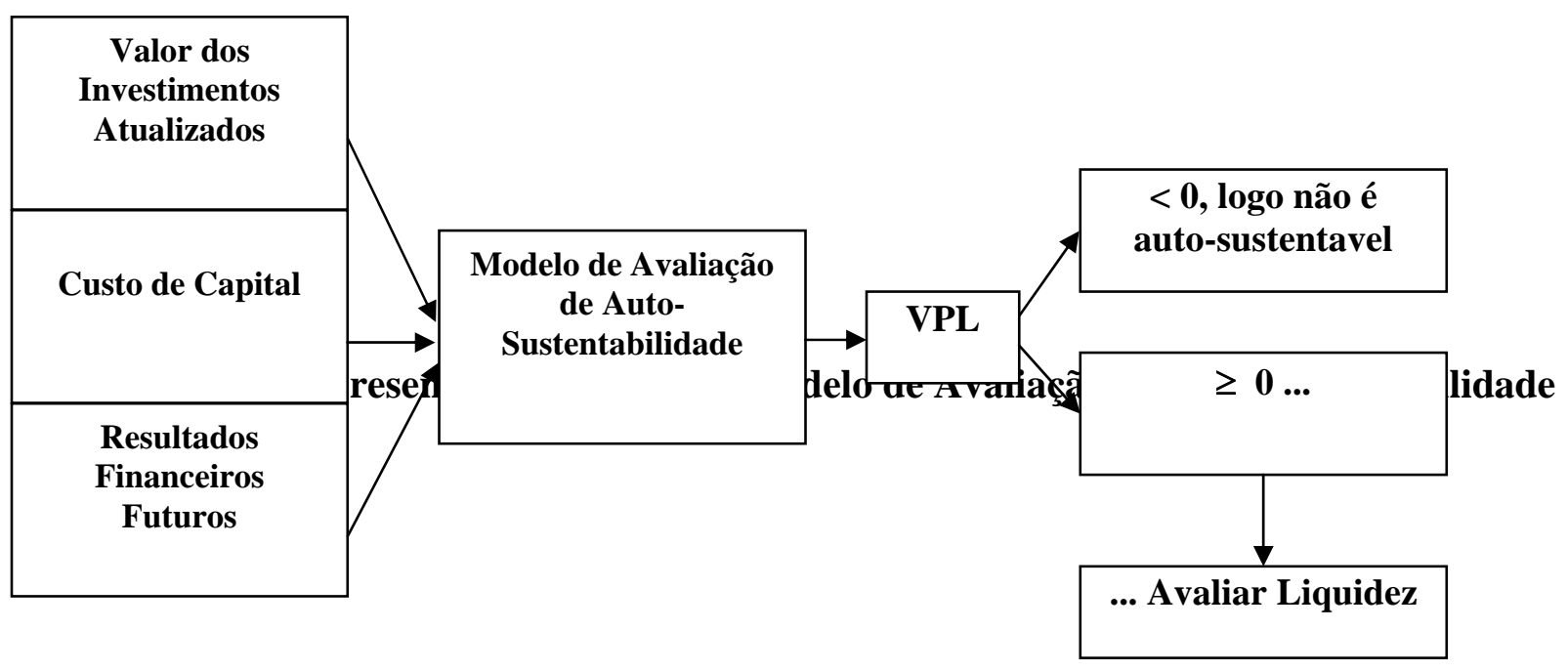

É possível, também com base no modelo de avaliação de auto-sustentabilidade, avaliar cada novo projeto de modo a verificar suas características e suas implicações na autosustentabilidade da rede. Trata-se de realizar análise aos fatores que geram autosustentabilidade aos novos projetos.

Também pode ser demonstrado no Modelo o detalhamento dos projetos de forma a verificar as características de cada um e suas implicações na auto-sustentabilidade de toda a rede.

Pode-se aplicar a utilização de outras taxas referentes ao Custo de Capital de cada projeto. Seriam as taxas devidamente calculadas por meio da metodologia CAPM. A utilização dessas taxas permite avaliar o risco inerente aos fluxos de caixa.

Com isso pode-se eliminar o risco de avaliar projetos como sendo agregadores de alto valor de auto-sustentabilidade quando, na verdade, apresentam baixo valor em virtude da aplicação de maior taxa de custo de capital decorrente do risco inerente ao projeto. Da mesma forma, pode-se eliminar a rejeição de projetos que envolvem pouco ou nenhum risco, em virtude de utilização de taxa de custo de capital menor, aumentando o valor de sustentabilidade. 
Diante do tema estudado verificou-se a relevância da necessidade que a INFRAERO possui de gerar recursos para colaborar com o desenvolvimento sustentável do Brasil. Esta empresa necessita manter seu negócio contínuo, haja vista que o seu sucesso resulta em desenvolvimento de infra-estrutura aeroportuária e aeronáutica que, por sua vez, proporciona os meios necessários para o desenvolvimento da aviação civil. A importância do desenvolvimento da aviação civil para o desenvolvimento brasileiro justificou a realização do presente trabalho de pesquisa.

O trabalho girou em torno de uma tentativa de definição de um modelo de avaliação de autosustentabilidade da INFRAERO. A hipótese formulada apresentou-se da seguinte forma:

É possível construir, com base em conceitos de avaliação de investimentos, um modelo de avaliação que permita aos gestores a verificação da auto-sustentabilidade da INFRAERO de modo a tomar decisões de investimentos que contribuam para o desenvolvimento sustentável do Brasil sem comprometer a saúde financeira da empresa.

Partiu-se dos conceitos encontrados na bibliografia acerca de sustentabilidade e definiu-se o que seria a auto-sustentabilidade no âmbito da pesquisa. Em seguida, obteve-se a representação matemática do modelo de avaliação de auto-sustentabilidade.

Porém, a avaliação de auto-sustentabilidade com base em conceitos de avaliação de investimentos esbarra numa limitação da aplicação da técnica do VPL. Esta técnica avalia a auto-sustentabilidade econômica, não considerando a liquidez dos investimentos ao longo de sua duração.

Isso quer dizer que mesmo que um dado projeto de investimento apresente VPL positivo, pode ser que durante sua vida útil ele possa apresentar resultado negativo em determinado período, não gerando recursos suficientes para se sustentar.

Portanto, a hipótese formulada é comprovada em parte. Pois foi possível desenvolver um modelo de avaliação que permite aos gestores a verificação da falta de auto-sustentabilidade 
da INFRAERO de modo a não decidir por investimentos que acabem com a capacidade de geração de recursos.

Conforme estudado no capitulo anterior, o modelo não se demonstra capaz de determinar a auto-sustentabilidade da INFRAERO, mas é capaz de demonstrar a não sustentabilidade dessa empresa quando for o caso.

Para que seja capaz de determinar a auto-sustentabilidade da INFRAERO, o modelo deve ser complementado com estudos sobre a liquidez de projetos de investimentos. Pois, somente será possível afirmar que a INFRAERO é auto-sustentável diante da realização de investimentos se for comprovada sua capacidade de geração oportuna de recursos, ou seja, geração de recursos quando da necessidade de realizar pagamentos.

Da forma como está desenvolvido, o Modelo é capaz de alertar para a realização de investimentos que prejudiquem a auto-sustentabilidade da empresa. Diante desse alerta, tornase dever dos gestores empreender ações no sentido de mitigar os custos e maximizar as receitas.

Os investimentos podem ser reavaliados no sentido de verificar o uso de tecnologias que proporcionem menor custo operacional dos aeroportos tais como algumas aplicações de automação aeroportuária. Novas oportunidades de atividades comerciais podem ser aproveitadas, sem comprometer a operação aeroportuária. A otimização dos processos no ramo da carga aérea em cada aeroporto pode ser empreendida.

Depois de todas essas ações, os projetos de investimentos podem ser selecionados prezandose pelo equilíbrio entre a política de desenvolvimento do país e a auto-sustentabilidade da INFRAERO, para que possa contribuir continuamente com esse desenvolvimento.

Enfim, a aplicação do Modelo pode implicar na melhora da gestão dos aeroportos em busca da auto-sustentabilidade da rede. Pois o Modelo valoriza implicitamente os processos de planejamento e execução além da avaliação. 
No entanto, para que o Modelo possa ser aplicado necessário se faz o desenvolvimento de trabalhos no âmbito da previsão e mensuração de resultados financeiros futuros de todas as dependências da INFRAERO.

Também é necessário realizar pesquisa de dados contábeis relativos aos desembolsos efetuados com recursos próprios dessa empresa a título de investimentos desde o início de seu negócio gerador de resultados mais antigo, atualizando esses valores para possibilitar sua comparação com valores presentes.

Outra questão que envolve a questão da auto-sustentabilidade e que necessita de estudo é a falta de termo jurídico de concessão de aeroportos à administração da INFRAERO. Conforme já demonstrado, não existe termo que defina as condições da exploração dos aeroportos, tais como prazos e valores. Existe o risco de que aeroportos superavitários sejam retirados sumariamente da tutela da INFRAERO, comprometendo a auto-sustentabilidade de toda a rede de aeroportos.

A utilização desse modelo no momento atual é pertinente, haja vista a iminência de utilização dos recursos previstos pelo Programa de Aceleração do Crescimento (PAC) do Governo Federal. Pois, mesmo que não houvesse a utilização de recursos próprios da INFRAERO, ela arcaria com os resultados financeiros futuros, sendo eles positivos ou não.

A INFRAERO pode orientar sobre a forma de realização dos investimentos com base no resultado encontrado em sua auto-sustentabilidade e no conhecimento das necessidades dos aeroportos. O encontro da auto-sustentabilidade da INFRAERO, com as necessidades da sociedade e com as políticas de desenvolvimento gerará o investimento ótimo, ou seja, o investimento que beneficia a sociedade como um todo. 
ARAÚJO, Edgilson T.; MELO, Vanessa P.; SCHOMMER, Paula C. O Desafio da Sustentabilidade Financeira e suas Implicações no Papel Social das Organizações da Sociedade Civil. V Conferencia Regional de ISTR, "Sociedad civil, participación ciudadana y desarrollo", 2005, Lima, Perú. Disponível em www.lasociedadcivil.org.

BRASIL, Ministério da Defesa, INFRAERO. Relatório Anual 2006, 2007.

BRASIL, Ministério da Defesa, INFRAERO. PLANO DE CONTAS COMENTADO DA EMPRESA BRASILEIRA DE INFRA-ESTRUTURA AEROPORTUÁRIA - Gerência de Contabilidade e Custos, 2005.

BRASIL, Ministério da Defesa, INFRAERO. www.infraero.gov.br.

CASAROTO FILHO, Nelson; KOPITTKE, Bruno Hartmut. Análise de Investimentos. 8. ed. São Paulo: Atlas, 1998.

DA SILVA, Adyr. Aeroportos e Desenvolvimento. 1. ed. Rio de Janeiro: Instituto HistóricoCultural da Aeronáutica; Belo Horizonte: Villa Rica, 1990.

FIPECAFI - Fundação Instituto de Pesquisas Contábeis, Atuariais e Financeiras. Manual de Contabilidade das Sociedades por Ações: aplicável ás demais sociedades. 5. ed. rev. e atual. São Paulo: Atlas, 2000.

GARRISON, Ray H.; NOREEN, Eric W. Contabilidade Gerencial. 9. ed. Rio de Janeiro: LTC Editora, 2001.

HENDRIKSEN, Elcon S.; BREDA, Michael F.V. Teoria da Contabilidade. 5. ed. Tradução de Antônio Zoratto Sanvicente. São Paulo: Atlas, 1999.

IUDÍCIBUS, Sérgio de. Teoria da Contabilidade. 6. ed. São Paulo: Atlas, 2000.

KUSTER, Edison; NOGACZ, Nilson D. Administração Financeira. UniFAE Centro Universitário. COLEÇÃO GESTÃO EMPRESARIAL, Volume IV - Finanças. Ed. Gazeta do Povo: 2002.

MATTAR NETO, João Augusto. Metodologia Científica na Era da Informática. 2. ed. São Paulo: Saraiva, 2005.

ROSS, Stephen A.; WESTERFIELD, Randolf W.; JORDAN, Bradford D. Princípios de Administração Financeira. $2^{\mathrm{a}}$ Edição. São Paulo: Atlas, 2000.

ROSS, Stephen A.; WESTERFIELD, Randolph W.; JAFFE, Jeffrey F. Administração Financeira. 2. ed. São Paulo: Atlas, 2002.

SILVA, José Pereira da. Análise Financeira das Empresas. 5. ed. São Paulo: Atlas, 2001. 